\title{
Scars of early non-employment for low educated youth: evidence and policy lessons from Belgium
}

\author{
Corinna Ghirelli ${ }^{1,2}$
}

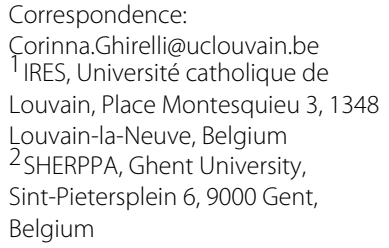

\begin{abstract}
This paper investigates whether the early experience of non-employment has a causal impact on workers' subsequent career. The analysis is based on a sample of low educated youth graduating between 1994 and 2002 in Flanders (Belgium). To correct for selective incidence of non-employment, we instrument early non-employment by the provincial unemployment rate at graduation. Since the instrument is clustered at the province-graduation year level and the number of clusters is small, inference is based on wild bootstrap methods. We find that one percentage point increase in the proportion of time spent in non-employment during the first two and a half years of the career decreases annual earnings from salaried employment six years after graduation by $10 \%$ and annual hours worked by $7 \%$ (unconditional effects). Thus, any policy that prevents unemployment in the first place will be beneficial. In addition, curative policies at the micro level may be required, depending on the actual cause of the scar.
\end{abstract}

JEL Classifications: J31; J64

Keywords: Youth unemployment; Scars; Instrumental variable; Wild bootstrap

\section{说) Springer}

\section{Introduction}

High levels of youth unemployment are a great concern for policy makers, especially since the start of the Great Recession (Bell and Blanchflower 2010). However, unemployment rates are typically higher for young workers than for older ones. This is understandable since younger workers have the least experience and hence are often the easiest to remove. Moreover, they lose or leave a job more often than older workers because job shopping helps them to find a good match (Gervais et al. 2014). For instance, Topel and Ward (1992) find that two thirds of job changes and wage growth occur in the first ten years of workers' career. This initial high turnover may involve also short spells in unemployment. Thus, youth unemployment need not be necessarily detrimental to workers' career if it is part of the process of finding stable employment. Other views predict that the experience of youth unemployment may entail long-term penalties in terms of reduced wages and persistent unemployment. These results are explained by human capital loss (Pissarides 1992), which may arise from the depreciation of existing capital as well as from forgone work experience (Ellwood 1982). Another explanation comes from the signaling

(c) 2015 Ghirelli. Open Access This article is distributed under the terms of the Creative Commons Attribution 4.0 International License (http://creativecommons.org/licenses/by/4.0/), which permits unrestricted use, distribution, and reproduction in any medium, provided you give appropriate credit to the original author(s) and the source, provide a link to the Creative Commons license, and indicate if changes were made. 
model in which past unemployment records are interpreted by employers as signals of low productivity in a context of imperfect information (Lockwood 1991).

Therefore, whether the early experience of non-employment entails long-term repercussions on youth's career should be assessed empirically. Our study addresses this research question for Flanders, the most prosperous of the three Belgian regions. The results of this analysis have important policy implications: namely, if the early experience of non-employment does not generate a scar on later labour market outcomes, there is no need for any policy intervention, since workers are themselves able to eliminate any negative impact on their career. By contrast, if it inflicts serious scarring effects, any policy that prevents unemployment in the first place will be beneficial.

Belgium is an interesting case because it has one of the most rigid labour markets among the OECD countries (Kawaguchi and Murao 2014). ${ }^{1}$ A related literature suggests that young graduates are more exposed to adverse labour market conditions at graduation in a rigid labour market than in a flexible one and that this exposure translates into more persistent penalties (e.g. Genda et al. 2010). Thus, we expect that, in Belgium, the early experience of non-employment inflicts large and long-lasting damages on youth's career.

Based on a very rich database combining survey with administrative data, we focus on a representative sample of low educated school-leavers graduating in Flanders in the 19942002 period and evaluate the impact of the early experience of non-employment on a range of later labour market outcomes: hours worked and earnings for salaried public and private sector employment as well as indicators of salaried and self-employment. This gives us a comprehensive view of the long-term consequences of the early experience of non-employment for low skilled workers.

The main identification problem is the presence of unobserved individual characteristics that may affect labour market performance as well as the (selective) incidence of early non-employment. This introduces an endogeneity problem in that the relationship between the early experience of non-employment and later labour market outcomes may be driven by individual unobservables rather than causality. We address this problem by means of an Instrumental Variable (IV) approach, where the provincial unemployment rate at graduation is used as instrument for early non-employment. The intuition is that the variation in the local unemployment rate at graduation is exogenous to the individual and therefore generates a variation in the early experience of non-employment that is unrelated to the unobserved factors that may influence both early and adult performances.

Thus, the IV strategy relies on the exogenous variation of the provincial unemployment rate at graduation to identify the long-term effects of early non-employment. Since the estimation includes province fixed effects, the identification exploits the time variation of the provincial unemployment rate series in the 1994-2002 period. Note, by including province fixed effects, we account for spacial sorting, that is, the possibility that individuals sort into provinces according to unobservable characteristics. Since the unemployment rate varies across 9 graduation years and 5 Flemish provinces, inference hinges at most on 45 clusters. This raises the possibility of underestimating standard errors due to few clusters. We tackle this problem by applying wild bootstrap methods to the IV approach, following Davidson and MacKinnon (2010).

The paper is organised as follows. The next section reviews the existing literature and points out the contribution of this paper. The data are described in Section 3. In Section 4 
we explain the estimation strategy: we discuss the IV approach, including the way in which we deal with the problem of inference with few clusters. Section 5 illustrates the results and presents some sensitivity analyses. Section 6 discusses the policy implications and Section 7 concludes.

\section{Literature review}

Our paper is related to several strands of literature. First, it pertains to the literature on the long-term impact of youth unemployment. This literature is quite rich and overall suggests that the consequences of experiencing youth unemployment are not just temporary. However, these studies tend to explore this effect each time on a single outcome. According to a number of them, the early experience of unemployment leads to subsequent unemployment (Gregg 2001 for UK, Schmillen and Umkehrer 2013 for Germany, Cockx and Picchio 2013 for Belgium). In addition, being unemployed when young is found to inflict persistent penalties on earnings (Gartell 2009 for Sweden, Gregory and Jukes 2001 for UK) and wages (Gregg and Tominey 2005 for UK, Mroz and Savage 2006 for US). Our research contributes to this literature by considering a range of labour market outcomes, thereby providing a comprehensive view of the long-term consequences of the early experience of non-employment on workers' careers.

Two studies have already investigated the long-term impact of unemployment for Belgium. On the one hand, Gangji and Plasman (2007) study the adverse effect of experiencing unemployment on re-entry wages based on a representative sample of Belgian workers aged 18-64 in the 1994-2002 period. ${ }^{2}$ They find that the incidence of unemployment reduces hourly wages by $5.1 \%$. Of course, this is an average of heterogenous effects, while unemployment is likely to have different consequences for young than for mature workers (Kletzer and Fairlie 2003). On the other hand, Cockx and Picchio (2013) investigate the long-run effects of youth long-term unemployment considering all Belgian school-graduates aged 18-25 who in 1998 were unemployed for at least 9 months. They find evidence of strong negative duration dependence in the job finding probability for this specific sub-sample. Relative to both studies, we provide new evidence on a representative sample of Flemish youth, i.e. less restrictive than long-term unemployed youth (as in the latter research) but more specific than the overall working-age population (as in the former one). Even if not directly comparable, our results are consistent with this evidence.

Moreover, this research is also related to a number studies that use the same IV approach to address the long-term effects of youth unemployment for different countries. $^{3}$ For the UK, Gregg (2001) and Gregg and Tominey (2005) use the local unemployment rate at age 16 as instrument for the unemployment experience between ages 16-23 and find that the latter generates long-lasting effects on later employment and wages, respectively. Similarly, for Germany, Schmillen and Umkehrer (2013) show that the unemployment experience in the first 8 years after graduation entails significant scars on the unemployment experience in the subsequent 16 years, instrumenting the former with the local unemployment rate at graduation. In a nutshell, all these studies exploit the exogenous variation of the local unemployment rate to disentangle the causality between the early experience of unemployment and later labour market performance from the spurious correlation induced by unobserved individual characteristics. In particular, the identification relies on the assumption that the early labour market conditions affect workers' career uniquely through the early experience of unemployment (exclusion 
restriction). As such, this is a strong assumption since it rules out the possibility that the aforementioned relationship occurs through other channels, i.e. the acceptance of lower-paying jobs early in the career.

Finally, our study is related to another strand of literature that focuses on the scarring effect of graduating in recessions on youth's careers. This literature is relevant to the extent that it sheds some light on the credibility of the aforementioned exclusion restriction, i.e. ultimately with respect to methodology. In fact, this research directly regresses the unemployment rate at graduation on later labour market outcomes to identify the adverse effect of graduating with high unemployment rates on different outcomes as well as its persistence over the labour market career. Thus, these results are relevant to our methodology because they provide intuitions about the underlying channels that drive such a scar. The intuition is that, if one uses the unemployment rate at graduation as an instrument for the early experience of non-employment in order to unveil the causality between the latter and later labour market performance, one relies on the exclusion restriction that early unemployment is the underlying channel that explains the longterm effects of graduating with high unemployment rates. Hence, evidence on which channel accounts for the scars of graduating in recessions may support or invalidate the exclusion restriction of our IV approach. The existing evidence broadly shows that the labour market conditions at graduation have a persistent impact on the labour market career of young graduates (e.g. Oreopoulos et al. (2012) for Canada, Kahn (2010) for US, Brunner and Kuhn (2014) for Austria). Among this literature, Cockx and Ghirelli (2015) offer a particularly relevant contribution by investigating the scarring effect of graduating in downturns for Flanders based on our data. Therefore, we use their results in order to improve the credibility of our exclusion restriction relative to the aforementioned literature that applies the same IV approach to study the long-term effects of youth unemployment for different countries.

Since our study builds upon the research of Cockx and Ghirelli (2015), we dedicate to this study the rest of the section. Overall, the authors show that graduating during downturns inflicts persistent penalties for both low and high educated Flemish youth but that this scar occurs though different channels depending on the educational level. This is because Belgian labour market institutions differ for white and blue collar workers, and this creates different sources of rigidities for these two groups. White collar workers are sheltered by a very strict employment protection legislation (EPL), which represents the main source of rigidity for these workers. By contrast, blue collar workers have quite loose $\mathrm{EPL}^{4}$ but are supported by short-term work compensation (STC) that subsidises a temporary reduction of labour force during downturns. This introduces rigidity in the labour market as it strongly restrains blue collar workers' mobility, thereby having similar consequences as EPL for white collar workers. In addition, the sectoral minimum wages are among the highest in the OECD. Thus, minimum wages and STC are more relevant sources of rigidity for low skilled workers.

Since the Belgian institutional setting generates different sources of rigidities for the white and blue collar workers, one would like to study these groups separately, but the choice between these workers' categories is clearly endogenously related to the labour market conditions and hence may induce selectivity. Thus, Cockx and Ghirelli (2015) distinguish between "low educated" (with at least secondary education) and "high educated" (with higher education) new graduates by exploiting two features of the data. First, 
there is a clear correspondence between low educated and blue collar workers as well as between high educated and white collar workers: within the first 6 years after graduation, $70 \%$ of low educated are prevalently employed as blue collar workers, while this figure corresponds only to $14 \%$ for the high educated (see Table 3 in Appendix A). Second, the moment of graduation - and hence the educational attainment-is found to be unrelated to the business cycle. ${ }^{5}$ In our study, we will rely on these arguments to select the low educated.

According to this research, graduating in downturns inflicts a scar on earnings for both the low and the high educated Flemish youth, but the low educated are penalised in terms of annual hours worked and not wages, while the reverse occurs for the high educated. Thus, due to unfavourable labour market conditions at graduation, the high educated downgrade to lower-paying jobs, whereas the low educated remain unemployed more often. ${ }^{6}$ This means that, in Flanders, the aforementioned scar on earnings occurs through different channels depending on the educational level, i.e. (i) the loss of early work experience for the low educated and (ii) the acceptance of lower-paying jobs for high educated (ii). Evidence (i) runs in favour of the identifying assumption required to study the long-term penalties of early non-employment by means of our IV approach. Since this evidence applies only to the low educated, we focus on the this group of workers.

\section{Data}

The analysis is based on the Sonar survey database, a representative sample of three birthcohorts of Flemish youth-born in 1976, 1978 or 1980-which were interviewed at age 23, 26 and 29. ${ }^{7}$ The surveys register retrospectively and on a monthly basis the most important activity of the respondents, among which education. Based on this information, graduation is identified to occur in the first month that education has been interrupted for more than 4 months. The surveys also contain control variables for the analysis, measured before the end of compulsory education (set at age 18 in Belgium) such that they are predetermined with respect to graduation: father's and mother's education, the type of educational programme in which the individual is enroled at age 17, and the number of repeated grades at age 17 since secondary education. ${ }^{8}$ In addition, we calculate for each individual the number of grades successfully passed from the start of secondary education until graduation. Accordingly, we divide the sample between low and high educated, with the former having completed at most secondary education and the latter having a higher level of education..$^{9}$ In doing this we follow Cockx and Ghirelli (2015) since the Belgian institutional setting entails different sources of rigidities for blue and white collar workers and because there is a clear correspondence between the educational level and the worker's function (see Section 2).

The original Sonar sample contains about 9,000 individuals, 3,000 for each birth cohort. We restrict it as follows. We exclude the few observations who dropped out from schooling before the end of compulsory education. We focus on men since female labour supply

is different from male labour supply due to mothering. ${ }^{10}$ To increase the homogeneity of the sample, we drop individuals who attended special needs and arts education, who were not Belgian or did not speak Flemish at home, or who did not reside in Flanders at graduation. We retain individuals graduating from age 18 and 24, as students graduating after 24 years old are less than $5 \%$ of the sample. After eliminating individuals with missing or 
inconsistent values in variables, we are left with a final sample of 3,586 low and high educated male youth. From this, we focus on 1,902 low educated youth who graduated in the period 1994-2002. Descriptive statistics of the final sample are in Appendix A.

The survey data are matched to administrative data of Belgian Social Insurance institutions centralised at the Cross Roads Bank of Social Security, which give us access to high quality information on workers' labour market history. These data report quarterly information on the registration as self-employed as well as earnings and time worked in dependent employment (for both public and private sector) between 1998 and 2010. We construct three employment indicators: salaried employment, defined by positive earnings from salaried employment; self-employment, based on the registration as selfemployed for at least one day during the calendar year; overall employment, which is the sum of self- and salaried employment. ${ }^{11}$ In addition, we construct a measure of annual earnings and hours worked for dependent employment.

For all outcomes we rely on linear models because our empirical strategy is already complicated by the IV approach combined with wild bootstrap methods. For binary outcomes we use linear probability models since OLS provide a good approximation of the of the average partial effects (APE) (Angrist and Pischke 2009, ch.3.4.2). As for hours worked, this variable is censored at zero. In principle, OLS are not consistent, while Tobit models are the appropriate estimation methods. However, since the fraction of corner solutions is quite small-only $15 \%$ of the sample-OLS still provide a good approximation of the APE on hours worked. ${ }^{12}$ By contrast, earnings are truncated, i.e. missing if individuals are not salaried employed. This may bias the results if salaried employed are a positively selective group. In principle, Heckman's 1979' selection model is the appropriate approach to address selectivity. Yet results can be very poor in absence of exclusion restrictions, as the equation of interest is only identified through the non-linearity of the Inverse Mills ratio-the term capturing selectivity (Puhani 2000). Unfortunately, we do not have a valid exclusion restriction for the selection equation. ${ }^{13}$ Ergo, results from the Heckman's selection model should not be trusted. To avoid selectivity, we set earnings to zero in case of non-employment, as if earnings were censored. This allows us to estimate unconditional effects and hence rule out the problem of selectivity due to restricting to salaried employed. As for hours worked, we check that OLS provide a good approximation of the APE of interest. ${ }^{14}$ Lastly, we transform the continuous outcomes in logs in order to interpret the coefficients as semi-elasticities. Note, before taking the logarithmic transformation we add value one so that non-salaried employed are retained in the analysis with zero log-earnings and zero log-hours worked. ${ }^{15}$ The outcomes are measured 6 years after graduation. This is because we want to measure the outcomes as late as possible for all graduation cohorts given the availability of the administrative data (1998-2010). ${ }^{16}$ Table 6 in Appendix A shows descriptive statistics of the outcome variables.

In addition, the administrative data provide additional controls measured at age 17: living in single parent household, not living together with either parents and the number of other household members by age class. Descriptive statistics of the controls are reported in Table 5 of Appendix A. ${ }^{17}$ Finally, the administrative data give us access to yearly information on the province of residence between the year in which the individual turns 17 and 2010.

From the year of graduation onwards, we associate each calendar year to a potential year of labour market experience, which corresponds to zero in the year of graduation. ${ }^{18}$ 
Potential experience zero lasts from the month subsequent to graduation until December of that calendar year so that its length is computed as (12 - month_of_graduation). All subsequent years of potential experience have a duration of 12 months. Our regressor of interest is a measure of the time spent in non-employment at potential experience $0-2$ relative to the potential total hours if one would work full-time during the whole period. We express it as a proportion in order to take into account the fact that the reference period changes depending on the month of graduation, thereby ensuring that early nonemployment is comparable across individuals. For a June graduate-which amounts to $90 \%$ of the sample-this period corresponds to two and a half years after graduation. For simplicity, hereafter we will refer to this reference period as its average, i.e. two and a half years after graduation.

This endogenous regressor can be measured precisely based on administrative data on hours worked in salaried employment. Yet, the latter are available since 1998, while graduation is observed since 1994. Thus, this variable is based on administrative data for students graduating since 1998 (68.5\% of the sample), while it is imputed using Sonar data whenever potential experience 0-2 occurs before 1998 (31.5\% of sample). The reason why we combine administrative with survey data is to maximize the sample and hence exploit the maximal instrument's variation considering the entire graduation period 1994-2002 instead of the restricted period 1998-2002. Of course, the disadvantage is that the Sonar dataset contains less precise information on time worked: this certainly introduces measurement error in the endogenous regressor. Briefly, the latter is constructed as follows (for details, see Appendix B): first, sum up all hours worked including self-employment in the first two and a half years after graduation $(a) ;{ }^{19}$ second, compute the potential total hours if one would work full-time during the whole period $(b)$; third, express early non-employment as $100 *(b-a) / b$. Given the possibility of measurement error arising from the combination of survey and administrative data, Section 5.1 performs a sensitivity analysis considering the restricted graduation period 1998-2002 where only administrative data are exploited to measure the endogenous regressor.

Finally, the Labour Force Survey (LFS) provides us with the provincial unemployment rate (15-64) for Flanders from year 1993 until 2011 (see Fig. 1), which we use as instrument for early non-employment. Note, the literature typically exploits more disaggregated unemployment rate series. ${ }^{20}$ For Belgium, provincial unemployment rates are the most disaggregated data available for the period considered. The main drawback is that inference relies on too few clusters as the identification of the effects of interest comes from the variation of the unemployment rates by provinces and years. Yet we tackle this problem with wild bootstrap methods. By contrast, a more aggregated series reduces the problem of endogenous migration, which may arise if workers offset the scars of early non-employment by moving or commuting in provinces where there are more jobs. Our data suggest that in Flanders less than $2 \%$ of individuals change province of residence in the 1998-2010 period. Yet, as Flanders is a relatively small region, people could commute to work across provinces. In this case, we would underestimate long-term effects of early non-employment. ${ }^{21}$ However, the magnitude of the inter-provincial variation in the unemployment rate reported in Fig. 1 demonstrates that mobility is limited and far from eliminates all inter-provincial variation. This is because LFS series are based on the province of residence and not of job location: thus, if workers commute to avoid 


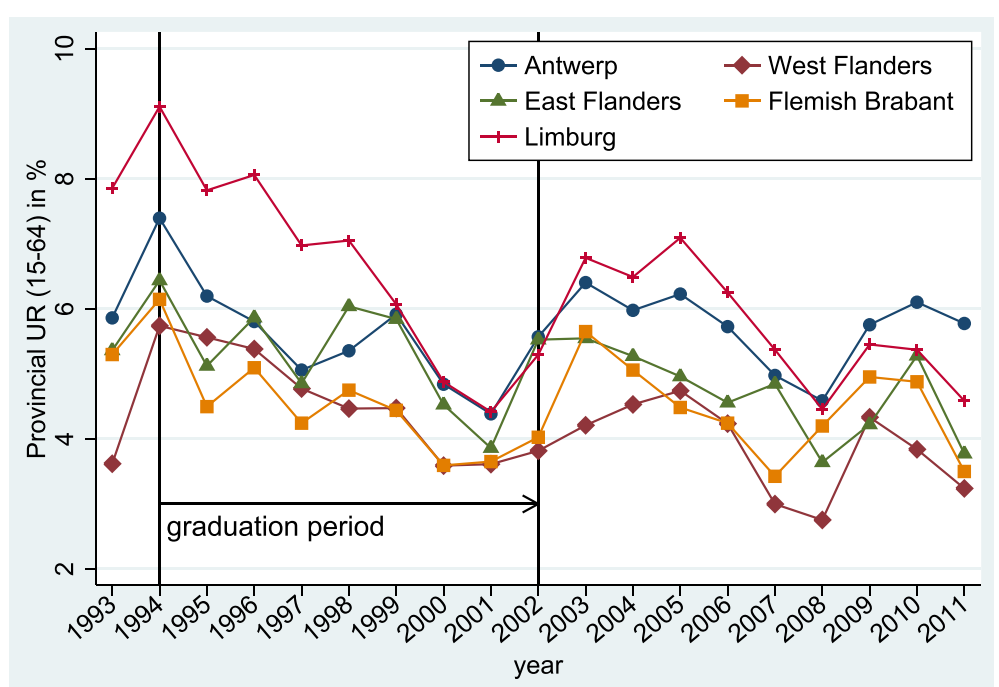

Fig. 1 Provincial unemployment rates (15-64) for Flanders: the graduation period for the low educated ranges between 1994-2002. For details on the series, see Section S.1.5 of "Additional file 1". Based on total population (men \& women). Source: Labour Force Survey

the adverse local labour market conditions, this evens out the provincial variation in the unemployment rate.

\section{Estimation strategy}

We are interested in the causality between the early experience of non-employment $\left(Y^{0}\right)$ and later labour market outcomes $(Y)$ for the low educated. Namely, we want to estimate an equation of the following type, where $X$ is a vector of control variables that will be defined below and $\epsilon$ is an idiosyncratic error term:

$$
Y=\alpha+\beta Y^{0}+\delta X+e \text { with } e=\theta+\epsilon
$$

The main identification problem is the presence of some unobserved factors $\theta$ that affect both early non-employment and later labour market performance, thereby introducing endogeneity. Thus, OLS estimates will be biased due to these omitted factors. We remove this bias by means of a two-stage least squares (2SLS) estimator in which the provincial unemployment rate at graduation is used as instrument $(Z)$ for early non-employment. ${ }^{22}$ In practice, the identification strategy relies on the variation of the provincial unemployment rate at graduation $Z$, which is exploited to generate an exogenous variation in the early experience of non-employment, which is then used to identify causality. In accordance with the traditional IV approach, we assume that the effect of interest is homogeneous. ${ }^{23}$ In this framework, 2SLS identify the causal effect of interest under two conditions:

1. $Z$ is uncorrelated with e. This implies that $Z$ does not directly affect the outcome $Y$ (exogeneity) and that any indirect effect of $Z$ on $Y$ occurs uniquely through the endogenous regressor $Y^{0}$ (exclusion restriction). This is an identifying assumption.

2. $Z$ is correlated with $Y^{0}$ conditional on controls $X$ (strength). This can be tested by means of the $F$ statistic of the excluded instrument in the first stage regression. 
Note, in this framework, the IV estimator refers to the entire population since the causal effect of interest is assumed to be homogeneous across individuals. The next section discusses in detail assumption 1. In particular, we will carefully examine which factors may violate the exclusion restriction and define the specification in such a way that the latter is most likely satisfied conditional on the covariates.

\subsection{The instrumental variable approach: identifying assumptions}

Together, Conditions 1 and 2 above require that the instrument explains the endogenous regressor while being exogenous in Eq. (1). This has the following implications.

First, it amounts to rule out reverse causality between, $Z$ and $Y^{0}$, that is the unemployment rate at graduation affects early non-employment but not the other way around. We exclude the possibility of reverse causality since the instrument and the endogenous regressor are measured at the provincial and individual level, respectively, and an aggregate variable cannot be caused by an individual variable.

Second, the exogeneity assumption in Condition 1 requires that the unemployment rate $Z$ does not affect the unobserved composition of new graduates by year and province. If this were the case, the relation between the instrument and early non-employment would spuriously reflect changes in the composition of graduates rather than causality, which would introduce selectivity. To rule this out, one has to assume that students choose the moment of graduation independently of the business cycle (exogeneity of the timing of graduation) and that before graduation they do not move to provinces where the unemployment rate is lower relatively to others (exogeneity of place). We test the former condition in Section S.5 of "Additional file 1" and demonstrate that the duration between the end of compulsory education and each year of potential graduation is unrelated to the provincial unemployment rate in those years. ${ }^{24}$ As for mobility, almost nobody $(0.44 \%)$ changes residence between the year in which the individual turns 17 and the year of graduation. Therefore, the issue can be safely ignored. ${ }^{25}$ On this basis, we argue that in our sample the choice of graduation is independent from the labour market conditions.

Third, the exclusion restriction in Condition 1 requires that the instrument is not correlated with any of the omitted factors in Eq. (1). This implies assuming that the scars of graduating in downturns for the low educated are determined exclusively by early non-employment. This assumption is consistent with the results of Cockx and Ghirelli (2015), who find that, for the low educated, the unemployment rate at graduation entails a persistent negative effect on hours worked and earnings but not on wages. This means that the low educated who graduate in downturns experience longer periods of nonemployment at the start of the career, and this has repercussions in the long-term. The absence of a negative impact on wages is due to the presence of high minimum wages, which are likely to be binding for low educated youth. This suggests that, for the low educated, accepting lower-paying jobs is not a relevant channel to explain the scarring effects of graduating in downturns. Thus, based on the aforementioned evidence, we argue that early non-employment is the relevant channel to explain such a scar for the low educated.

Of course things can be a bit more blurry if we consider a wider definition of reservation wage which also incorporates the future wage growth linked with seniority in addition to the current wage. In this case, the low educated graduating in a downturn may 
not only experience higher early non-employment, but could also accept lower-quality jobs, i.e. with a less steep wage profile than the jobs accessed during a tight labour market. The unemployment rate at graduation would then entail a growing negative impact on later wages as a consequence of accepting this initial job, and this would represent a violation of the exclusion restriction when wages are the outcome of interest. Thus, we do not consider later wages as an outcome variable. By contrast, we restrict the analysis to hours worked and earnings, since the long-term penalties on the these outcomes are compatible with the idea that early non-employment is the main driver of these scars.

However, other channels may also contribute to explain the long-term penalties of labour market conditions at graduation: these channels would invalidate the exclusion restriction if not included in the specification. An example is the persistence of the unemployment rate series. If the current unemployment rate affects the outcomes, the correlation between the former and the unemployment rate at graduation violates the assumption that the instrument affects the outcomes only through early non-employment. To prevent that, it is important to additionally control for the current unemployment rate. Yet, this may not be enough, as in principle one should control for all unemployment rate series up to the moment of evaluation (Oreopoulos et al. 2012, 2008). To keep a parsimonious specification, we add the average unemployment rate between the end of the early period and the moment of evaluation-between potential experience 3 and $6 .^{26}$

More generally, the problem of the persistence of the unemployment rate refers to the literature on wage determination (Beaudry and DiNardo 1991). According to this view, labour markets operate as spot markets if current wages are affected by the current unemployment rate and not by past ones. By contrast, wages result from long-term implicit contracts if past unemployment rates explain current wages: in addition, with costless mobility, the minimum unemployment rate since hiring should matter the most, as workers are able to renegotiate the wage once better labour market conditions arise. In this case, the exclusion restriction may be violated if the unemployment rate at graduation mistakenly picks up the effect of the minimum unemployment rate since hiring because of the persistence of the unemployment rates. To prevent that, we include the minimum unemployment rate since graduation in the specification. ${ }^{27}$

Finally, other violations of the exclusion restriction may be due, for instance, to differences in institutions that could be correlated both with the unemployment rate at graduation and with the outcomes. We therefore include province fixed effects to ensure that permanent differences across provinces do not violate the exclusion restriction. Similarly, we include province-specific time trends to capture whatever time-varying provincial heterogeneity, such as changes in legislations, that may be correlated with the instrument and the outcomes. In the next section we present the equation of interest in light of all these arguments.

\subsection{The equation of interest}

To avoid clutter, we state the following definitions: $t$ is the observation period which runs from graduation until the moment in which the outcomes are measured $(T)$, i.e. 6 years after graduation; $t_{0}$ is the year in which students are aged 17, i.e. before the end of compulsory education; $t_{1}$ is the time window in which we measure early non-employment, 
on average the first two and a half years after graduation. ${ }^{28}$ We estimate the following equation, where subscript $i$ indicates the individual, $g$ the graduation year and $p$ the province of residence at graduation:

$$
\begin{aligned}
& y_{i g p T}=\alpha+\beta y_{i t_{1}}^{0}+\gamma_{1} U R_{p T}+\gamma_{2} \overline{U R}_{p}+x_{i t_{0}}^{\prime} \delta+\zeta \min U R_{p t}+\eta_{p}+\omega_{p} T+f(g)+e_{i g p T} \\
& \text { with } e_{i g p T}=\theta_{i}+\epsilon_{i p g T}
\end{aligned}
$$

- $y_{i g p T}$ represents the following outcomes: three indicators of salaried, self- and overall employment, as well as log hours worked and log earnings for salaried employment.

- $y_{i t_{1}}^{0}$ is the endogenous regressor representing early non-employment: it is expressed as the percentage of time spent in non-employment in period $t_{1}$, relative to potential total hours if one would work full-time during the whole period.

- $U R_{p T}$ is the current unemployment rate in the province of residence at graduation. It ensures that the exclusion restriction is not violated by the correlation between the current labour market conditions and the labour market conditions at graduation.

- $\overline{U R}_{p}$ is the time average of the unemployment rate in the period subsequent to the early period, i.e. from potential experience 3 to 6 . Together with $U R_{p T}$, it controls for the persistence of the unemployment rate series.

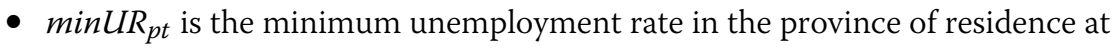
graduation over the entire period $t$. It controls for the possibility that wages are determined by long-term contracts and renegotiated by the workers during upturns.

- $x_{i t_{0}}$ is a set of individual control variables, predetermined since measured in $t_{0}$ : birth cohort dummies, family composition, parental education, repeated years since secondary education as well as the educational track at age 17 .

- $\eta_{p}$ are fixed effects for the province of living at graduation: they control for all differences across provinces that are constant over time, e.g. differences in institutions or in the structure of the economy. This also controls for spatial sorting.

- $\omega_{p} T$ are province-specific linear time trends, included since the provincial unemployment rates exhibit differential downward time trends (see Fig. 1). In addition, this controls for any time-varying provincial heterogeneity.

- $f(g)$ is a linear spline in the graduation year, which controls for aggregate shocks affecting all provinces over the graduation period. ${ }^{29}$ The spline is formulated as $f(g)=\alpha+\sum_{j=0}^{2} \beta_{j} .(g-3 j) \mathbf{1}[g \geq 3 j]$ with $g=1, . ., 9$.

- $\epsilon_{i g p T}$ is an i.i.d. error term, while $\theta_{i}$ represents unobserved individual factors that are correlated with $y_{i t_{1}}^{0}$ and hence introduce endogeneity.

$\beta$ is the coefficient of interest representing the scarring effect of a one percentage point $(p p)$ increase in the proportion of time spent in early non-employment on the outcomes (employment rates, hours worked and earnings) for the low educated: in presence of scarring we expect a negative $\beta$. The OLS estimate of $\beta$ is biased due to the correlation between $\theta_{i}$ and $y_{i t_{1}}^{0}$. We remove this bias by instrumenting $y_{i t_{1}}^{0}$ with the provincial unemployment rate at graduation in the IV approach.

Note, we cannot control for the labour market performance in the intermediate period (i.e. between potential experience 3-5) because it is endogenous. ${ }^{30}$ Thus, $\beta$ is an average between the direct effect of the early experience of non-employment and its persistence over time. The latter represents the extent to which the early labour market performance is correlated with the labour market performance in the intermediate period, which in 
turn is correlated with the labour market performance at the moment of evaluation (e.g. through state dependence). We believe that $\beta$ still provides an interesting measure of the scars of early non-employment although we are not able to further disentangle (i) the direct effect of the early experience of non-employment from (ii) the effect of the experience of non-employment in the intermediate period which is consequence of early non-employment. ${ }^{31}$

For simplicity, we estimate (2) by OLS and 2SLS for all dependent variables. Thus, for binary outcomes we use linear probability models. For continuous outcomes we report unconditional effects ignoring that they are left-censored at zero. However, linear methods still provide a good approximation of the APE of interest on the censored outcomes (see Section 3 and endnotes 12 and 14).

\subsection{The bias and its direction}

The aforementioned bias can go in both directions. The latter depends on the sign of the relationship between the omitted factor and the outcome as well as on the sign of the covariance between the omitted factor and early non-employment. Below we discuss four possible sources of bias and their corresponding sign.

- Ability and motivation: everything else equal, higher ability and motivation are associated with better performance in the labour market: thus these factors are correlated negatively with early non-employment and positively with the outcomes. The overall bias is negative so that OLS overestimate the (negative) scarring effect of early non-employment.

- Returns to job search: ceteris paribus, individuals with higher returns to job search are expected to search more and more successfully and hence perform better in the labour market (positive correlation with the outcomes). At the same time, they may engage in "job shopping" early in the career and alternate jobs with short spells in non-employment if they find it optimal to consume leisure when young. ${ }^{32}$ This generates a positive correlation between returns to search and early non-employment (Neumark 2002). Accordingly, the bias is positive and OLS underestimate scarring.

- Liquidity constraints: liquidity-constrained individuals have a low reservation wage and hence are likely to accept the first job offer even though this means taking a low-level job. Thus, we expect liquidity constraints to be negatively correlated with early non-employment but also to translate into worse labour market performance over time (i.e. negative correlation with the outcomes). The resulting bias is positive so that OLS underestimate scarring.

- Measurement error: measurement error in the endogenous regressor reduces OLS estimates towards zero (Hausman 2001), thereby underestimating the scarring effect of early non-employment. We introduce measurement error in the construction of early non-employment, as we use information from the Sonar database to impute hours worked in the first two and a half years after graduation for students graduating before 1998, which are not observed in the administrative data (see Section 3).

To recapitulate, we expect OLS to overestimate the scarring effect of early nonemployment on the outcomes if the bias comes from ability. By contrast, OLS will underestimate this scar if the bias is due to returns to job search, measurement error 
in the endogenous regressor, or liquidity constraints. The literature is in favour of the latter hypothesis (Gregg 2001; Gregg and Tominey 2005; Neumark 2002; Schmillen and Umkehrer 2013).

\subsection{Inference}

It is well known that standard errors are underestimated in a micro-level regression with grouped covariates because it is assumed that each observation is independent of all others, while the independent information of the grouped covariates varies at the group level. Thus, correct inference requires taking this into account by using cluster-robust standard errors (Moulton 1990). In our 2SLS this is important because we use the provincial unemployment rate at graduation, a grouped variable, as the instrument for early non-employment, which varies at the individual level. Thus, the identification of causality comes from the aggregate variation of the unemployment rate at graduation, which is exploited to construct the fitted values of the first stage (Angrist and Pischke 2009, ch.8).

The clustered estimator is consistent provided that the number of clusters is large enough, as consistency is determined by the law of large numbers. Since we consider the low educated graduating in 5 Flemish provinces in the 1994-2002 period, inference hinges on 44 clusters. $^{33}$ This raises the possibility of underestimating standard errors due to few clusters. Applying the clustered estimator when clusters are too few is likely to worsen the bias, with cluster-robust standard errors being even smaller than the conventional ones (MacKinnon and Webb 2015). This is what we find by comparing heteroskedastic-robust and cluster-robust standard errors of 2SLS estimations (see Table 1), which suggests that we have too few clusters.

We tackle this problem with wild restricted efficient residual bootstrap methods proposed by Davidson and MacKinnon (2010), which are designed for 2SLS in the context of heteroskedasticity or clustered data. This procedure combines the restricted efficient residual bootstrap designed by Davidson and MacKinnon (2008) for 2SLS with the wild bootstrap of Cameron et al. (2008) that allows for intra-cluster correlation and heteroskedasticity. For completeness, we apply wild bootstraps to the $t$ statistic of the instrument in the first stage as well as to the $t$ statistic of the regressor of interest when estimating Eq. (2) by OLS. ${ }^{34}$

Because of few clusters, the F statistic of the first stage is also overestimated. To adjust it, we exploit the fact that in case of one instrument the $F$ statistic is the square of the $t$ statistic of the instrument in the first stage: i.e., with $G$ clusters, $F(1, G-1)=t^{2}(G-1)$. Therefore, the bootstrap F statistic is the critical value of the $F(1, G-1)$ distribution that corresponds to the bootstrap P-value of the $t$ statistic of the instrument in the first stage. $^{35}$

\section{Results}

Table 1 summarizes the main results for alternative labour market outcomes. As a matter of space, we report only the effect of early non-employment estimated by OLS and 2SLS, i.e. $\beta$ in the structural equation as well as the impact of the instrument in the first stage regression. The complete regressions are reported in Appendix C. Odds and even columns show heteroskedastic-robust ${ }^{36}$ and cluster-robust standard errors, respectively. In principle, the latter are more conservative since they allow for the intra-cluster correlation induced by the fact that the instrument is a grouped variable. 
Table 1 Effect of interest on outcomes measured 6 years after graduation

\begin{tabular}{|c|c|c|c|c|c|}
\hline \multicolumn{6}{|c|}{ Panel A: Effect of early non-employment in the structural equation: } \\
\hline & \multirow[b]{2}{*}{ Standard errors ${ }^{a}$} & \multicolumn{2}{|c|}{ OLS } & \multicolumn{2}{|c|}{$2 S L S$} \\
\hline & & $\begin{array}{l}\text { Robust } \\
\text { (1) }\end{array}$ & $\begin{array}{c}\text { Cluster } g * p \\
\text { (2) }\end{array}$ & $\begin{array}{l}\text { Robust } \\
\text { (3) }\end{array}$ & $\begin{array}{c}\text { Cluster } g * p \\
\text { (4) }\end{array}$ \\
\hline \multirow[t]{5}{*}{ Salaried empl. } & coeff & $-0.00169^{* * *}$ & $-0.00169^{* * *}$ & -0.00256 & -0.00256 \\
\hline & se & $(0.00034)$ & $(0.00041)$ & $(0.00375)$ & $(0.00290)$ \\
\hline & $P$-val & & 0.00019 & & 0.38202 \\
\hline & Bootstrap $P$-val ${ }^{b}$ & & 0 & & 0.45646 \\
\hline & Exogeneity test $P$-val ${ }^{C}$ & & & & 0.767 \\
\hline \multirow[t]{5}{*}{ Self-empl. } & coeff & $0.00054^{*}$ & 0.00054 & 0.00248 & 0.00248 \\
\hline & se & $(0.00030)$ & $(0.00041)$ & $(0.00338)$ & $(0.00258)$ \\
\hline & $P$-val & & 0.19177 & & 0.34175 \\
\hline & Bootstrap $P$-val & & 0.18619 & & 0.37437 \\
\hline & Exogeneity test $P$-val & & & & 0.438 \\
\hline \multirow[t]{5}{*}{ Overall empl. } & coeff & $-0.00115^{* * *}$ & $-0.00115^{* * *}$ & -0.00008 & -0.00008 \\
\hline & se & $(0.00021)$ & $(0.00025)$ & $(0.00207)$ & $(0.00151)$ \\
\hline & $P$-val & & 0.00005 & & 0.95655 \\
\hline & Bootstrap $P$-val & & 0 & & 0.96697 \\
\hline & Exogeneity test $P$-val & & & & 0.467 \\
\hline \multirow[t]{5}{*}{ Log earnings } & coeff & $-0.0269^{* * *}$ & $-0.0269^{* * *}$ & $-0.1002^{* *}$ & $-0.1002^{* * *}$ \\
\hline & se & $(0.0033)$ & $(0.0040)$ & $(0.0419)$ & $(0.0291)$ \\
\hline & $P$-val & & $2.51 \mathrm{E}-08$ & & 0.0013 \\
\hline & Bootstrap $P$-val & & 0 & & 0.0060 \\
\hline & Exogeneity test $P$-val & & & & 0.00970 \\
\hline \multirow[t]{5}{*}{ Log hours worked } & coeff & $-0.0203^{* * *}$ & $-0.0203^{* * *}$ & $-0.0723^{* *}$ & $-0.0723^{* * *}$ \\
\hline & se & $(0.0024)$ & $(0.0029)$ & $(0.0307)$ & $(0.0207)$ \\
\hline & $P$-val & & 9.35E-09 & & 0.0011 \\
\hline & Bootstrap $P$-val & & 0 & & 0.0060 \\
\hline & Exogeneity test $P$-val & & & & 0.0112 \\
\hline \multicolumn{6}{|c|}{ Panel B: Effect of the instrument in the first stage: OLS } \\
\hline Outcome: & Standard errors: & Robust & Cluster $g * p$ & & \\
\hline \multirow[t]{6}{*}{ Early non-empl. } & coeff & $5.4615^{* * *}$ & $5.4615^{* * *}$ & & \\
\hline & se & $(1.7273)$ & $(1.6848)$ & & \\
\hline & $P$-val & & 0.00230 & & \\
\hline & Bootstrap $P$-val & & 0.00400 & & \\
\hline & F stat & & 10.51 & & \\
\hline & Bootstrap F stat ${ }^{d}$ & & 9.25 & & \\
\hline
\end{tabular}

Standard errors between parentheses. Panel A reports results from estimating $\beta$ in Eq. (2). $\beta$ is the effect of one $p p$ increase in $y_{i t{ }^{\prime}}^{0}$ i.e. the $\%$ of hours spent in non-employment in the first two and a half years after graduation relative to potential total hours if one would work full-time during the whole period. For clustered standard errors, we report the

$P$-value and the wild bootstrap $P$-value. Column 1-2 (3-4) show OLS (2SLS). In 2SLS the provincial unemployment rate at graduation is used as instrument for $y_{i t_{1}}^{0}$. Panel $B$ shows the effect of the instrument on $y_{i t_{1}}^{0}$ in the first stage and the corresponding F statistic ${ }^{* * *} p<0.01,{ }^{* *} p<0.05,{ }^{*} p<0.1$

${ }^{a}$ Robust accounts for heteroskedasticity. Clusters are defined by graduation year $g$ and province of residence at graduation $p$ ( $G=44$ clusters)

${ }^{b}$ Computed according to the wild bootstrap proposed by Davidson and MacKinnon (2010) for 999 repetitions

'With clustered standard errors, this test is defined as the difference between two Sargan-Hansen statistics: one for the equation where $y_{i t_{1}}^{0}$ is treated as endogenous and one for the equation where $y_{i t_{1}}^{0}$ is treated as exogenous. Under the null that $y_{i t_{1}}^{0}$ is exogenous, the statistic is distributed as $\chi^{2}(1)$

${ }^{d}$ Bootstrap F statistic is the F statistic corresponding to the bootstrap $P$-value of the t statistic of the instrument: we rely on the equivalence between $F$ and $t$ distribution: for $G=44, t^{2}(G-1)=F(1, G-1)$

However, the fact that the 2SLS cluster-robust standard errors are smaller than the 2SLS heteroskedastic-robust ones (columns 3 and 4 in Panel A) suggests that clustering is ineffective because of too few clusters. We ensure that correct inference is being made by 
bootstrapping the $t$ statistic of the effect of interest and by reporting the corresponding P-value.

Panel B summarises the results of the first stage regression. We report the original $\mathrm{F}$ statistic (10.51) as well as the bootstrap one (9.25), which accounts for the problem of few clusters. As expected, the former is overestimated. According to the Stock-Yogo critical values, this statistic indicates that the IV estimator of $\beta$ over-rejects the null, as it leads to a rejection rate close to $15 \%$ when the true rejection rate is $5 \%$ (Stock and Yogo 2005). ${ }^{37}$ Thus, due to this test size, IV estimates should be taken with caution.

The upper part of Panel A refers to the employment indicators. The sign of the estimates suggests that early non-employment has a positive impact on the probability to be selfemployed and a negative impact on the probability to be salaried employed, but the size of both effects is very small. In contrast to OLS, 2SLS are not significant: this may be because of the too small power of the test due to the limited strength of the instrument. The null hypothesis of the exogeneity test is largely not rejected for all indicators, ${ }^{38}$ suggesting that both estimators are consistent but OLS is more efficient than 2SLS. We therefore focus on the former: for one $p p$ increase in early non-employment, the probability to be salaried employed and overall employed decrease by $0.17 \%$ and $0.12 \%$, respectively. These effects are statistically significant. Self-employment increases by $0.05 \%$, but the impact is statistically insignificant.

More significant effects are shown in the bottom part of Panel A, which reports the unconditional effect of interest on continuous outcomes. The null of the exogeneity test is rejected in all cases, meaning that the 2SLS estimator is consistent as opposed to the OLS. A comparison between the estimates suggests that OLS underestimate the scarring effect of early non-employment. This is in line with the hypothesis that the bias is caused by returns to search, liquidity constraints or measurement error in the endogenous regressor, and consistent with what found in the literature. The 2SLS results indicate that one $p p$ increase in early non-employment reduces earnings and hours worked by $10 \%$ and $7 \%$, respectively (column 4 ). Both estimates are highly significant (at $1 \%$ level). Yet, the P-values of column 4 may be underestimated due to few clusters. We tackle this by computing the bootstrap P-value for the $\mathrm{t}$ statistic of $\beta$. The latter is higher than the P-value of clustered standard errors, but still lower than 0.05 . Thus, the impact of early non-employment on continuous outcomes remains significant even allowing for few clusters.

These estimates suggest that the low educated who experience early non-employment at the start of the career are still significantly penalised in terms of hours worked and earnings 6 years after graduation. The results on hours worked are not directly comparable but consistent with the existing literature, which reports persistent effects of early unemployment on later unemployment. However, our results are somewhat larger. For British low educated youth, Gregg (2001) finds that a 3-months increase in the unemployment duration before age 23 significantly increases the time out of work between age 28 and 33 by 2 months. Schmillen and Umkehrer (2013) obtain larger effects based on new graduates from the German apprenticeship programme: one additional day of unemployment during the first 8 years after graduation increases unemployment in the following 16 years by 0.96 days-almost a one to one change. The larger scar estimated for Belgium may be explained by the Belgian institutional setting, which leads to high labour market rigidities, as argued in Section 2. 
Tables 7 and 8 in Appendix C show the entire OLS and 2SLS regressions for continuous and binary outcomes, respectively. The individual controls show the expected signs: in the first stage regression, grade repetition in secondary education is positively associated with early non-employment, while technical, vocational and apprenticeship programmes are associated with a lower proportion of time spent in early non-employment compared to general education (column 5 of Table 7). This suggests that these programmes improve school-to-work transition relative to general education. Note that mother's education is positively associated with early non-employment in the first stage and with the probability to be self-employed in the OLS regression, but it is negatively associated with the outcomes related to salaried employment: we do not have a clear explanation for this finding.

\subsection{Sensitivity analysis}

As a first sensitivity analysis, we want to rule out that the results of Table 1 are driven by multicollinearity, which may arise because in Eq. (2) we include a number of controls for the persistence of the unemployment rate: the current unemployment rate $\left(U R_{p T}\right)$, the average unemployment rate since the end of the early period and the moment of evaluation $\left(\overline{U R}_{p}\right)$, and the minimum unemployment rate since graduation $\left(\min U R_{p t}\right)$. To check this, we rerun the model by including only the current unemployment rate (thereby excluding $\overline{U R}_{p}$ and $\min U R_{p t}$ ): the results of this restricted specification are reported in Table 9 of Appendix D. The stability of the results ensures that multicollinearity is not driving the results.

As a second sensitivity analysis, we assess the impact of measurement error in the endogenous regressor, which arises from the combination of survey and administrative data. In fact, early non-employment is measured precisely for individuals graduating in the 1998-2002 period based on administrative data, but it is imputed for those graduating in the 1994-1997 period based on the Sonar database (see Appendix B for details). This allows us to maximize the variation of the instrument considering the entire graduation period 1994-2002 at the cost of introducing some measurement error in the endogenous regressor. To check to what extent measurement error affects the results, we rerun the analysis by restricting the sample to graduation period 1998-2002 so that the endogenous regressor is measured uniquely by administrative data. Of course, clusters are drastically reduced from 44 to $24 .{ }^{39}$ This is problematic not only because it exacerbates the problem of few clusters, but also because Eq. (2) contains too many parameters $(k=30)$ compared to the number of clusters, and as a consequence the rank condition in 2SLS is not satisfied. ${ }^{40}$ Thus, we need to reduce the parameters in Eq. (2).

We decide to exclude some of the non-significant individual controls and to keep in the specification all the aggregate regressors, which are important to ensure the validity of the exclusion restriction. ${ }^{41}$ In particular, we drop the following controls that are jointly not significant at the $5 \%$ level according to an $\mathrm{F}$ test in the first stage regression: dummy for living with single parent, dummy for not living with parents, number of household members aged 12-17, 18-29, 30-64, 65+ (we keep the number of household members aged $0-11$ since it is significant); plus, we aggregate all educational tracks different from general education (technical, vocational, part-time education or apprenticeship) and include a dummy for general education instead. ${ }^{42}$ Table 11 shows that results are robust to this alternative specification, as the OLS estimate of the endogenous regressor is very stable 
in the full specification (column 1 and 4) and in the restricted specification (column 2 and 5), provided that both specifications are based on the graduation period 1994-2002.

Panel B of Table 10 reports the first stage regression for the 1998-2002 period. This table should be compared to Table 1. First, the bootstrap F statistic is 3.6 for the graduation period 1998-2002 compared to 9.2 for the period 1994-2002, therefore, the instrument becomes weak by restricting to the former period. As expected, the increased discrepancy between the original $\mathrm{F}$ and the bootstrap F statistic in Table 10 compared to Table 1 shows that the few-clusters bias worsens significantly when shifting from 44 to 24 clusters. Second, the direct effect of the instrument on early non-employment for the 1998-2002 period doubles compared to the period 1994-2002. This is because the former period focuses on the dot-com recession, whose effects are mitigated when a larger span is considered. Given the low F statistic, 2SLS are not reliable.

However, we can focus on the OLS results in Table 11 to shed some light on the importance of measurement error in the endogenous regressor. In principle, this should bias the OLS estimates for the 1994-2002 period (Column 1 and 4) towards zero. Yet, the OLS estimates for the 1998-2002 period (Column 3 and 6) should not at all be affected by measurement error since the endogenous regressor is entirely measured by administrative data. Thus, we compare the first row across columns (column 1 with 3 and column 4 with 6): for both outcomes, the estimates are close, but the one based on the 1994-2002 period is slightly smaller than the corresponding estimate for the 1998-2002 period. This is consistent with the presence of measurement error in the endogenous regressor. However, this difference is small $(0.2 p p)$; thus, we conclude that measurement error in early non-employment is not a major issue in the analysis.

\section{Policy implications}

According to our results, the early experience of non-employment entails important penalties on the labour market career of low educated youth. These scars may be originated by the human capital depreciation occurring in the unemployment spell, by the foregone human capital that would have been accumulated in case of early work experience, or because the early experience of non-employment is interpreted as a signal of low quality. Even though this study does not allow to discern the actual source of the scar, it makes clear that some policy interventions are needed.

At a micro level, one can think of specific curative policies to reduce the impact of early non-employment depending on the channel through which the scar materialises. If human capital depreciation is the main source of the scar, training schemes targeting young unemployed would be an appropriate cure. If instead the main cause of the scar is the loss of early work experience, policies that foster the integration of youth into the labour market should be advocated, such as wage subsidy programmes. However, if the cause is rather the bad signals conveyed by the unemployment status, it is likely that entering in subsidised programs would not improve how the young unemployed are perceived by the employers.

In addition, an efficient way to tackle the aforementioned scars is to prevent the experience of unemployment in the first place. Therefore, policy interventions at an aggregate level should strive to reach a successful macroeconomic framework with high sustained levels of employment. The latter can be achieved by a flexicurity system, where a flexible labour market is associated with a generous insurance system that provides for the 
unemployed. On the one hand, flexibility should be enhanced to encourage employers to take entrepreneurial risks and create more jobs. This is because labour market rigidities hamper productivity growth if they prevent worker reallocation or new hirings due to high expected firing costs in future downswings. On the other hand, a generous UI system should compensate workers for bearing a higher risk of unemployment due to the increased flexibility in the labour market. Thus, in the context of flexicurity, low hiring costs should enhance workers reallocation and new hirings as well as decrease the expected duration of unemployment, thereby fostering early work experience. Yet, less employable individuals may be long-term unemployed. This group should be supported by active labour market programmes as well as training schemes to improve their labour market prospects.

Belgian low educated workers face a number of rigidities which restrain worker' reallocation or new hirings. A first example is the STC programme, which anchors blue collar employees to their employers in recessions and hence increases the expected future costs of new hirings. A second rigidity is represented by high minimum wages, which limit the absorption of low educated youth for whom minimum wages are binding. A third one is the asymmetry between the flexible EPL for blue collars and a rigid EPL for white collars, which characterised the Belgian labour market until 2013. Note that this controversial discrimination has been removed since the beginning of 2014 as a single employment contract has been introduced, stipulating the same EPL for white and blue collar workers.

Although this study concerns the cohorts that graduated in the period 1994-2002, the policy lessons drawn in this section could be extended to neighboring periods in which similar variations in the provincial unemployment rates occurred. In the 1994-2002 period, a typical downturn entailed an average increase in the provincial unemployment rate of $1.4 p p .{ }^{43}$ This variation is similar to the one that occurred in the Great Recession in 2008 when the provincial unemployment rates rose on average by $1.6 p p$. Thus, we expect that the negative consequences of early non-employment for the cohorts that graduated during the Great Recession could be even larger than those found in this study. Therefore, the aforementioned policy recommendations should also apply to the Great Recession period.k

\section{Conclusions}

This study investigates the causal impact of the early experience of non-employment on later labour market outcomes for a sample of low educated youth graduating in the 19942002 period in Flanders, the most prosperous of the three Belgian regions. Our research question is complicated by the fact that the early experience of non-employment is correlated with unobserved individual factors which also affect later labour market outcomes. This makes our regressor of interest endogenous due to an omitted variable problem.

The case of Belgium is particularly interesting because it is characterised by one of the most rigid labour markets in the OECD. In addition, Belgian labour market institutions entail different sources of rigidities for blue and white collar workers. Cockx and Ghirelli (2015) provide evidence that, because of these differences, the scar of graduating in downturns occurs through the loss of early work experience for the low educated and through the acceptance of lower-paying jobs for the high educated.

In this study, we define the empirical strategy in light of these results. We focus on the low educated and address the endogeneity problem by means of an IV approach in which 
the provincial unemployment rate at graduation is used as an instrument for the early experience of non-employment. The evidence provided by Cockx and Ghirelli (2015) ensures that the exclusion restriction is most likely satisfied since the scar of graduating in downturns is found to occur through the loss of early work experience for the low educated. Throughout the article we discuss the assumptions required by the IV estimator, their validity and the role they play in the identification of causality between the early experience of non-employment and later labour market outcomes. The problem of few clusters is addressed by wild bootstrap methods.

We find that a one $p p$ increase in the time spent in non-employment in the first two and a half years since graduation decreases earnings from salaried employment 6 years after graduation by $10 \%$ and annual hours worked by $7 \%$. These effects are unconditional on being salaried employed. To counteract these scars, any policy that prevents unemployment in the first place will be beneficial. At the aggregate level, policy interventions should aim for a successful macroeconomic framework with sustained high levels of employment. The latter can be facilitated by the introduction of a flexicurity system. To the extent that this strategy is not fully successful, specific curative policies at the micro level will be required, such as training schemes or wage subsidies to target unemployed youth.

\section{Endnotes}

${ }^{1}$ Kawaguchi and Murao (2014) construct a composite index to rank the OECD countries according to their labour market rigidity: Belgium is at the top of this ranking.

${ }^{2}$ For UK Arulampalam (2001) finds similar results for workers aged 18-64 in 1991-1997.

${ }^{3}$ Neumark (2002) identifies the causality of early job stability on adult wages with IV by instrumenting indicators of early job stability with early labour market conditions.

${ }^{4}$ Note that since the beginning of 2014 a single employment contract has been introduced in Belgium, stipulating the same EPL for white and blue collar workers.

${ }^{5}$ This evidence is relegated to Section S.5 of "Additional file 1".

${ }^{6}$ The high educated downgrade due to strict EPL for white collars. The low educated experience higher unemployment because of the higher competition for lower-paying jobs. Their wages are not affected as minimum wages are likely to be binding for low educated youth.

${ }^{7}$ For more details, see Sonar $(2003,2004 a, b)$.

${ }^{8}$ Parental education is defined as years of completed education since age 12 . The type of educational programme in which the individual is enrolled at age 17 can be general, technical, vocational, part-time vocational or apprenticeship.

${ }^{9}$ The low educated have at most 6 years of completed education (7 years if enroled in vocational track at age 17).The high educated have higher years of completed education.

${ }^{10}$ For women this research question is equally interesting and left for future research.

${ }^{11}$ Salaried employed who are also registered as self-employed in the same calendar year are considered self-employed since the latter are few relative to salaried employed: at potential experience $6.84 \%$ are only salaried employed, $7 \%$ are only self-employed and $5 \%$ are both salaried and self-employed.

${ }^{12}$ To get some sense of it, we estimated Eq. (2) by OLS and Tobit on hours worked and checked that the corresponding APE of interest are very similar: the OLS coefficient is -0.0203 and the APE after Tobit is -0.0231 . Full results available upon request.

${ }^{13}$ Following Puhani (2000), we test for the presence of multicollinearity by looking at the $R^{2}$ after regressing the covariates on the Inverse Mills Ratio: $R^{2}=0.95$ suggests very high multicollinearity. Exercise available upon request.

${ }^{14}$ We estimated Eq. (2) by OLS and Tobit on earnings: the OLS coefficient is -0.0269 and the APE after Tobit is -0.0307 . Full results available upon request.

${ }^{15}$ In a log-level regression, the coefficient of $X$ on $\log (Y)$ is interpreted as the \% change of $Y$ for a unit increase in $X$ (semi-elasticity). In our case, the coefficient of interest is only "approximatively" a semi-elasticity, given that the dependent is $\log (Y+1)$. Yet we verified that this interpretation is a good approximation (exercise available upon request). 
${ }^{16}$ Results are similar when the outcomes are measured at potential experience 8 , albeit the instrument is weaker due to the smaller sample: exercise available upon request.

${ }^{17}$ For details on control and outcome variables see Section S.1 of "Additional file 1".

18 "Potential" underlines that the variable counts all calendar years since graduation as opposed to actual experience, which endogenously considers only years of employment.

${ }^{19}$ For self-employed we assume the working regime of full-time salaried employed.

${ }^{20}$ At the district level (Schmillen and Umkehrer 2013) and at the ward level (Gregg 2001; Gregg and Tominey 2005).

${ }^{21}$ If anything, this should be more worrying for the high educated as they are (i) less liquidity constrained due to high expected wages or better working conditions and (ii) more mobile due to high motivation to find jobs that meet their expectations.

${ }^{22}$ A similar approach has been used by Neumark (2002), Schmillen and Umkehrer (2013), Gregg (2001) and Gregg and Tominey (2005).

${ }^{23}$ This assumption is restrictive. Under heterogeneous effects, the IV estimator identifies a weighted average of local average treatment effects (LATE). Yet this requires additional hypotheses, Stable Unit Treatment Value Assumption and Monotonicity, which are very difficult to hold in our case as they rule out crowding-out effects in the labour market.

${ }^{24}$ In a discrete duration model, an indicator of graduating since age 17 is regressed on birth cohort dummies, individual controls and the province of living at age 17 , the elapsed duration in education since age 17, and the unemployment rate in each potential year of graduation (interacted with the elapsed duration), testing if the coefficients of latter interactions are jointly significantly different from zero. The test deals with selectivity induced by unobserved heterogeneity. It uses the same sample as this study. For details, see Section S.5 of "Additional file 1 ".

${ }^{25}$ Students may endogenously commute to attend universities in provinces where they expect to find jobs after graduation. Yet, this is not an issue, as the instrument is measured in the province of residence at graduation and not in which they attend university.

${ }^{26}$ We run a sensitivity analysis only including current unemployment rate (see Table 9 in Appendix D). The stability of the results rules out multicollinearity.

${ }^{27}$ The hypothesis of long-run implicit contracts is more likely for the high educated to capture returns in human capital accumulation. Yet, low-skilled labour markets are shown to operate like spot markets (Devereux and Hart 2007; Kilponen and Santavirta 2010).

${ }^{28}$ This time window corresponds to potential experience $0-2$, i.e. from the month after graduation until December of the second subsequent calendar year.

${ }^{29}$ We impose a piece-wise linear specification because graduation year fixed effects absorb too much variation and as a consequence the instrument becomes weaker in the first stage.

${ }^{30} \mathrm{Gregg}$ and Tominey (2005) face the same problem and adopt the same solution. They study the causality between the unemployment experience at ages 16-23 and wages at age 33, instrumenting the former with the local unemployment rate at age 16. In the IV estimation they do not control for the unemployment experience at ages 23-33 (see Table 5) since their empirical strategy does not allow to deal with both endogeneity problems. They control for it only in the OLS (see Table 3) where the endogeneity is not addressed.

${ }^{31}$ I thank the anonymous referee for raising this point.

${ }^{32}$ Neumark (2002) justifies this hypothesis by arguing that, in a standard life cycle utility-maximization model, individuals are more likely to consume leisure at the point in the life cycle when their wages are low.

${ }^{33}$ Cluster $g 2002 p 3$ is empty. Table 4 in Appendix A shows the distribution across clusters.

${ }^{34}$ In the first stage the instrument is grouped so we need to cluster. Yet, clustering is not a major issue in the OLS estimation since the endogenous regressor varies at the individual level. For completeness we provide heteroskedastic- and cluster-robust standard errors.

${ }^{35}$ We are aware of only one study (Baltagi et al. 2013) on the performance of wild bootstrap applied to the F statistic in context of heteroskedastic (but not clustered) data. Bootstrapping the F test directly in our wild bootstrap procedure does not always yield the expected results (sometimes the bootstrap $P$-value of the F statistic is smaller than the $P$-value of the original F). Thus, we rely on the bootstrap $P$-value of the $t$ statistic of the instrument in the first stage.

${ }^{36}$ When the dependent variable is binary or censored, the conditional variance $(\operatorname{Var}(y \mid x))$ is unlikely to be constant, i.e. errors are heteroskedastic. 
${ }^{37}$ With one instrument, the critical value for maximal size test of $10 \%$ and $15 \%$ is 16.3 and 8.96 , respectively.

${ }^{38}$ This is not corrected for the few clusters problem. Thus, the $P$-value may be too small.

${ }^{39}$ In principle, 5 years times 5 provinces, i.e. $G=25$. Yet, $g 2002 p 3$ is empty.

${ }^{40}$ The Variance-Covariance matrix of the moment conditions has size $(30 \times 30)$ and rank equal to 24 (Baum et al. 2003).

${ }^{41}$ Compared to aggregate controls, individual controls play a minor role since they alleviate the problem of omitted individual variables, which is anyway tackled by IV.

${ }^{42}$ Reference is a category for technical, vocational, part-time education, and apprenticeship.

${ }^{43}$ This period encompasses the dot-com recession, which occurred in Belgium between March 2001 and November 2001. This showed up in the provincial unemployment rates that in Flanders rose between 2001-2003 and did not fall before 2005 (see Fig. 1).

\section{Appendix}

\section{A Description of the final sample}

In this study we consider almost the same sample as in Cockx and Ghirelli (2015). They consider 1,885 low educated youth, while we consider 1,902 individuals: i.e. we add 17 low educated individuals who graduated in 2002. Table 2 shows the distribution of attained education for the final sample before dropping the high educated (for the low and the high educated together): attained education is measured as the number of grades successfully completed since the start of secondary education. In the analysis we focus only on the low educated youth. For details in the construction of the control and outcome variables, see Section S.1, S.2 and S.3 of "Additional file 1".

\section{B Construction of the endogenous regressor}

We define potential experience as a variable counting each calendar year since graduation. Potential experience zero corresponds to the year of graduation and runs from the month after graduation until December of that calendar year; therefore, it potentially lasts less

Table 2 Dividing the sample between the low and the high educated

\begin{tabular}{cccc}
\hline Completed education & Low educated & High educated & Total \\
\hline 1 & 2 & & 2 \\
2 & 36 & 36 \\
3 & 89 & 89 \\
4 & 113 & 113 \\
5 & 185 & 289 & 185 \\
6 & 1,111 & 55 & 1,111 \\
7 & 366 & 707 & 655 \\
8 & & 367 & 55 \\
9 & & 232 & 707 \\
10 & & 33 & 367 \\
11 & & 1 & 232 \\
12 & 1,902 & 1,684 & 33 \\
13 & & 1 \\
Total & & 3,586 \\
\hline
\end{tabular}


Table 3 Correspondence between educational level and worker's function

\begin{tabular}{|c|c|c|c|c|c|c|}
\hline \multicolumn{7}{|c|}{ Function undertaken 6 years after graduation ${ }^{a}$} \\
\hline & \multicolumn{3}{|c|}{ Low educated } & \multicolumn{3}{|c|}{ High educated } \\
\hline & Freq. & Percent & Cum. & Freq. & Percent & Cum. \\
\hline Blue collar & 1,193 & 62.72 & 62.72 & 184 & 10.93 & 10.93 \\
\hline White collar & 390 & 20.5 & 83.23 & 1,193 & 70.84 & 81.77 \\
\hline Functionary & 68 & 3.58 & 86.8 & 105 & 6.24 & 88 \\
\hline Missing & 251 & 13.2 & 100 & 202 & 12 & 100 \\
\hline Total & 1,902 & 100 & & 1,684 & 100 & \\
\hline \multicolumn{7}{|c|}{ Prevalent function undertaken up to 6 years after graduation ${ }^{b}$} \\
\hline & \multicolumn{3}{|c|}{ Low educated } & \multicolumn{3}{|c|}{ High educated } \\
\hline & Freq. & Percent & Cum. & Freq. & Percent & Cum. \\
\hline Blue collar & 1,346 & 70.77 & 70.77 & 235 & 13.95 & 13.95 \\
\hline White collar & 401 & 21.08 & 91.85 & 1,337 & 79.39 & 93.35 \\
\hline Functionary & 53 & 2.79 & 94.64 & 36 & 2.14 & 95.49 \\
\hline Missing & 102 & 5.36 & 100 & 76 & 4.51 & 100 \\
\hline Total & 1,902 & 100 & & 1,684 & 100 & \\
\hline
\end{tabular}

${ }^{a}$ t refers to the type of function undertaken at potential experience 6

${ }^{b}$ It refers to the function undertaken more than $50 \%$ of the time from graduation up to potential experience $6.70 \%$ of low educated are prevalently employed as blue collars while this figure is only $14 \%$ for the high educated. Thus, there is clear correspondence between low educated and blue collar workers and between high educated and white collar workers

than 12 months ( 6 months for a student graduating in June). By contrast, potential experience one runs from January until December of the subsequent calendar year, thereby lasting 12 months. Subsequent potential experience years are defined similarly.

The regressor of interest is the percentage of hours spent in non-employment at potential experience $0-2$, relative to potential total hours if one would work full-time during the whole period. We express everything in hours because this is the smallest unit of measurement used in the administrative data (it is used to measure time worked in part-time employment). The reference period is computed considering the entire calendar year for potential experience one and two and the part of the calendar year following the month of graduation for potential experience zero. That is, for one who graduated in June, the time spent working at potential experience $0-2$ is divided by the total working hours in 30 months of full-time salaried employment.

Define $a$ as the total hours worked (including self-employment) at potential experience $0-2$ and $b$ the potential total hours if one would work full-time during the whole period;

Table 4 Number of individuals by graduation year and province of residence at graduation

\begin{tabular}{ccccccc}
\hline & \multicolumn{5}{c}{ Low educated } & \\
\cline { 2 - 5 } grad_year & prov1 & prov2 & prov3 & prov4 & prov5 & Total \\
\hline 1994 & 30 & 9 & 31 & 48 & 25 & 143 \\
1995 & 47 & 22 & 44 & 48 & 48 & 209 \\
1996 & 84 & 45 & 65 & 85 & 38 & 317 \\
1997 & 78 & 41 & 65 & 67 & 36 & 287 \\
1998 & 111 & 46 & 78 & 90 & 61 & 386 \\
1999 & 99 & 42 & 47 & 64 & 47 & 299 \\
2000 & 56 & 18 & 30 & 28 & 31 & 163 \\
2001 & 26 & 8 & 11 & 17 & 18 & 80 \\
2002 & 10 & 3 & 0 & 2 & 3 & 18 \\
Total & 541 & 234 & 371 & 449 & 307 & 1902 \\
\hline
\end{tabular}

The analysis considers the graduation period 1994-2002 for the low educated. The combination g2002 \& prov 3 is excluded since empty. The province of residence is measured on December 31 of each year between the year in which the individual turns 17 and 2010. Provinces of residence at graduation are in the following order from 1 to 5: Antwerp, Flemish Brabant, Western Flanders, Eastern Flanders, Limburg. Each combination of graduation year and province of residence at graduation represents a cluster gp in the main analysis 
Table 5 Descriptive statistics of individual control variables

\begin{tabular}{lcccccc}
\hline Variable & Obs & Mean & Std. Dev. Min & Max Label \\
\hline Birth cohort76 & 1902 & 0.33 & 0.47 & 0 & 1 & 1 if born in 1976 \\
Birth cohort78 & 1902 & 0.33 & 0.47 & 0 & 1 & 1 if born in 1978 \\
Birth cohort80 & 1902 & 0.34 & 0.47 & 0 & 1 & 1 if born in 1980 \\
Live in single-parent & 1902 & 0.12 & 0.33 & 0 & 1 & 1 if live with single parent at age17(Dec) \\
Not live with parents & 1902 & 0.06 & 0.24 & 0 & 1 & 1 if not live with either parents at age17(Dec) \\
HH members aged 0-11 & 1902 & 0.25 & 0.62 & 0 & 7 & nr of other HH members aged0-11 at age17(Dec) \\
HH members aged 12-17 & 1902 & 0.51 & 0.69 & 0 & 7 & nr of other HH members aged12-17 at age17(Dec) \\
HH members aged 18-29 & 1902 & 0.52 & 0.73 & 0 & 8 & nr of other HH members aged18-29 at age 17(Dec) \\
HH members aged 30-64 & 1902 & 1.89 & 0.40 & 0 & 5 & nr of other HH members aged30-64 at age 17(Dec) \\
HH members aged 65+ & 1902 & 0.04 & 0.21 & 0 & 2 & nr of other HH members aged65+ at age17(Dec) \\
Father education & 1902 & 4.59 & 3.20 & 0 & 13 & Father completed education since age12 \\
Mother education & 1902 & 4.21 & 3.06 & 0 & 13 & Mother completed education since age12 \\
Years of delay in sec.edu & 1902 & 0.83 & 0.84 & -1 & 4 & Years of delay at age17(Aug) \\
General education & 1902 & 0.11 & 0.31 & 0 & 1 & 1 if general edu at age17(Aug) \\
Technical education & 1902 & 0.38 & 0.49 & 0 & 1 & 1 if technical edu at age 17(Aug) \\
Vocational education & 1902 & 0.41 & 0.49 & 0 & 1 & 1 if vocational edu at age17(Aug) \\
Apprenticeship/PT edu & 1902 & 0.10 & 0.30 & 0 & 1 & 1 if apprenticeship/PT edu at age17(Aug) \\
\hline
\end{tabular}

The statistics are reported for the sample of interest, i.e. the low educated graduating in the period 1994-2002

then the regressor of interest is computed as $100 *(b-a) / b$. Below we explain in detail how these components are constructed.

1. Construct a according to the following steps.

I. $\quad a$ is mostly based on the total hours worked in salaried employment and the date of registration and cancellation from the self-employment register based on administrative data. Since hours worked are not available for self-employment, we assume that the latter work as much as a full-time salaried worker: i.e. 5 days per week and 8 hours per day until 2002 and 5 days per week and 7.6 hours per day from 2003 onwards. This is due to the introduction of a new law that changed the daily working hours from 8 to 7.6 since January 2003 in Belgium. Whenever one combines self-employment and salaried-employment in the same quarter, we make the same assumption so that the hours worked do not exceed the bounds.

Table 6 Descriptive statistics of outcomes measured at potential experience 6

\begin{tabular}{|c|c|c|c|c|c|c|}
\hline Variable & Obs & Mean & Std. Dev. & Min & Max & Label \\
\hline \multicolumn{7}{|c|}{ Continuous outcomes in level } \\
\hline Earnings & 1902 & 19277.29 & 10978.69 & 1 & 47551 & Yearly gross earnings from salaried empl.+1 \\
\hline Hours worked & 1902 & 1390.923 & 725.0779 & 1 & 2265 & Yearly hours worked in salaried empl.+1 \\
\hline \multicolumn{7}{|c|}{ Continuous outcomes in log } \\
\hline Log earnings & 1902 & 8.42 & 3.59 & 0 & 10.77 & Log (yearly gross earnings from salaried empl.+1) \\
\hline Log hours worked & 1902 & 6.20 & 2.67 & 0 & 7.73 & Log (yearly hours worked in salaried empl.+1) \\
\hline \multicolumn{7}{|c|}{ Binary outcomes } \\
\hline Self-empl. & 1902 & 0.12 & 0.33 & 0 & 1 & 1 if only pos. earnings from salaried ( $\&$ not self-empl) \\
\hline Salaried empl. & 1902 & 0.84 & 0.37 & 0 & 1 & 1 if registered as self-empl. \\
\hline Overall empl. & 1902 & 0.96 & 0.20 & 0 & 1 & 1 if pos.earnings from salaried or registered as self-empl. \\
\hline \multicolumn{7}{|c|}{ Endogenous regressor } \\
\hline Early non-empl. & 1902 & 30.60 & 29.65 & 0 & 100 & \% hours not worked relative to FT salaried empl. \\
\hline
\end{tabular}


II. The construction of a requires an additional adjustment due to the limited availability of the administrative data, which cover the period 1998-2010. Since the sample contains 3 birth cohorts $(1976,1978,1980)$ and that compulsory education ends at age 18 in Belgium, these data can be used in the following cases (68.5\% of the final sample): all individuals born in 1980, those born in 1978 graduating at least at age 20 and those born in 1976 graduating at least at age 22. Figure 2 summarises the availability of the data. To retain in the analysis students born in 1976 graduating between ages 18-21 as well as students born in 1978 graduating between ages 18-19 (which correspond to $31.5 \%$ of the final sample), we exploit the monthly working status from the Sonar database and impute the values of a following the procedure used for self-employed workers. That is, for each month in which the individuals are working according to Sonar, we attribute the working hours of a full-time salaried worker: i.e. 8 working hours per day until 2002 and 7.6 working hours per day strictly after 2002. For the entire observation period, we consider 21.6 working days per month (assuming 65 working days in a quarter gives 21.6 working days per month: $21.6 \times 3=65$ ).

2. Construct $b$. Recall that it is defined as the potential total hours if one wold work full-time during potential experience $0-2$. As for a, we consider a full-time working regime of 5 days per week and 8 hours per day until 2002 as well as 5 days per week and 7.6 hours per day from 2003 onwards. This gives a total of 2,080 annual working hours until 2002 (8 hours/day $\times 65$ days/quarter $\times 4$ quarters/year) and 1,976 annual working hours from 2003 onwards $(7.6$ hours/day $\times 65$ days/quarter $\times$ 4 quarters/year).

3. The regressor of interest is computed as $(b-a) / b * 100$ and hence ranges between $[0,100]$. In some cases ( $10 \%$ of the final sample) this percentage is negative because of overtime work. Therefore, it is censored at zero.

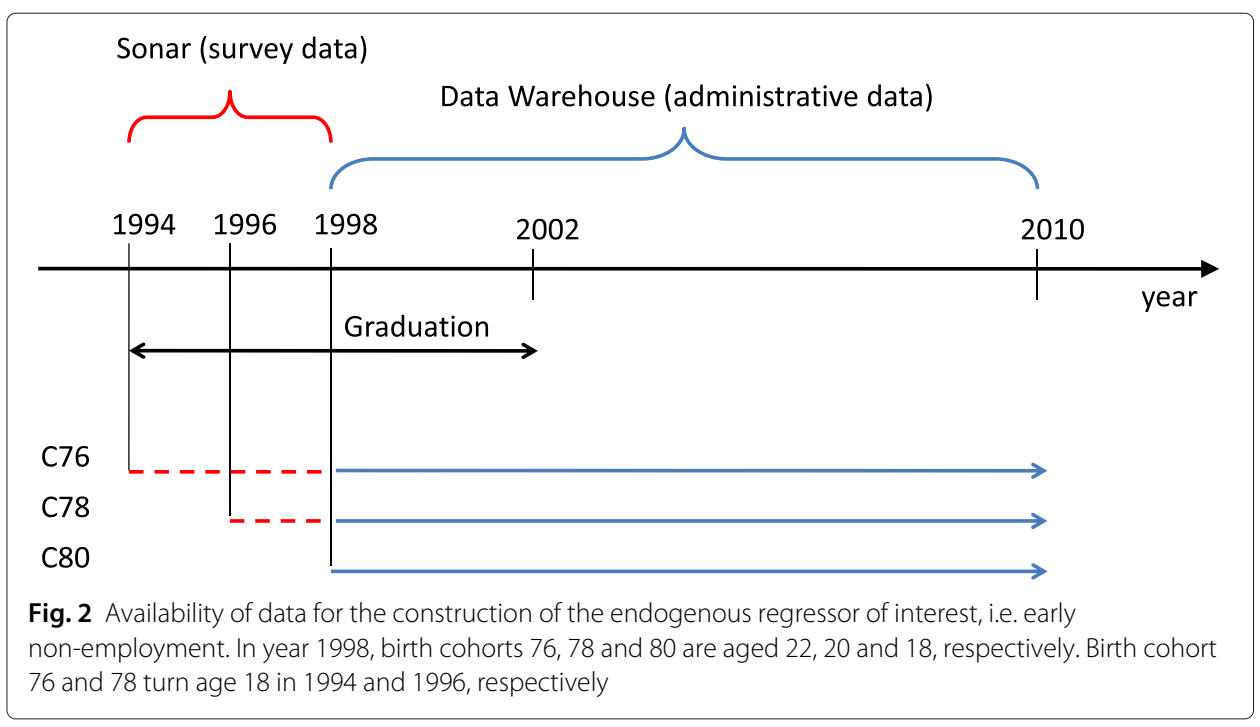




\section{Complete results}

Table 7 Complete estimations on continuous outcomes

\begin{tabular}{|c|c|c|c|c|c|}
\hline \multirow{3}{*}{ Outcomes ${ }^{a}$} & \multicolumn{4}{|c|}{ Second stage on continuous outcomes } & \multirow{3}{*}{$\begin{array}{c}\text { First stage } \\
\text { Early non-empl. } \\
\text { OLS }\end{array}$} \\
\hline & \multicolumn{2}{|c|}{ Log earnings } & \multicolumn{2}{|c|}{ Log hours worked } & \\
\hline & OLS & $2 S L S$ & OLS & $2 S L S$ & \\
\hline \multirow[t]{2}{*}{ Clustered standard errors: } & $g * p$ & $g * p$ & $g * p$ & $g * p$ & $g * p$ \\
\hline & & $(2)$ & (3) & (4) & (5) \\
\hline \multirow[t]{2}{*}{ UR_grad } & & & & & $5.4615^{* * *}$ \\
\hline & & & & & $(1.6848)$ \\
\hline \multirow[t]{2}{*}{ Early non-empl. } & $-0.0269^{* * *}$ & $-0.1002^{* * *}$ & $-0.0203^{* * *}$ & $-0.0723^{* * *}$ & \\
\hline & $(0.0040)$ & $(0.0291)$ & $(0.0029)$ & $(0.0207)$ & \\
\hline \multirow[t]{2}{*}{ UR_pe6 } & $0.4823^{* *}$ & $0.4172^{* *}$ & $0.3341^{* *}$ & $0.2880^{* *}$ & 0.3779 \\
\hline & $(0.1904)$ & $(0.1919)$ & $(0.1382)$ & $(0.1392)$ & $(1.6071)$ \\
\hline \multirow[t]{2}{*}{ lin_grad_year } & -0.1588 & 0.0469 & -0.1139 & 0.0319 & 3.5329 \\
\hline & $(0.2945)$ & $(0.2995)$ & $(0.2134)$ & $(0.2191)$ & $(2.2946)$ \\
\hline \multirow[t]{2}{*}{ lin_grad_year|trend >3 } & $0.9033^{* *}$ & 0.6407 & $0.6676^{* *}$ & 0.4814 & -4.4281 \\
\hline & $(0.4003)$ & $(0.4242)$ & $(0.2915)$ & $(0.3109)$ & $(2.8479)$ \\
\hline \multirow[t]{2}{*}{ lin_grad_year|trend >6 } & $-0.4604^{*}$ & -0.4394 & $-0.3335^{*}$ & -0.3186 & 3.9169 \\
\hline & $(0.2582)$ & $(0.2852)$ & $(0.1866)$ & $(0.2036)$ & (3.1378) \\
\hline \multirow[t]{2}{*}{ d_province2 } & $-1.3812^{*}$ & -1.2603 & $-0.9479^{*}$ & -0.8622 & 3.6574 \\
\hline & $(0.7107)$ & $(0.9544)$ & $(0.5041)$ & $(0.6684)$ & (8.6769) \\
\hline \multirow[t]{2}{*}{ d_province3 } & $-2.1753^{* * *}$ & $-2.9226^{* * *}$ & $-1.5774^{* * *}$ & $-2.1070^{* * *}$ & -11.7452 \\
\hline & $(0.6066)$ & $(0.9315)$ & $(0.4344)$ & $(0.6703)$ & $(8.9621)$ \\
\hline \multirow[t]{2}{*}{ d_province4 } & 0.0841 & 0.1824 & 0.0740 & 0.1436 & 0.7495 \\
\hline & $(0.4801)$ & $(0.4983)$ & $(0.3504)$ & $(0.3570)$ & $(4.7080)$ \\
\hline \multirow[t]{2}{*}{ d_province5 } & 0.8990 & 0.9210 & 0.6674 & 0.6829 & $-15.1893^{* *}$ \\
\hline & $(0.6099)$ & $(0.6721)$ & $(0.4495)$ & $(0.4866)$ & $(6.6042)$ \\
\hline \multirow[t]{2}{*}{ lin_calend_year_prov2 } & 0.0498 & 0.0410 & 0.0349 & 0.0287 & 0.0774 \\
\hline & $(0.1386)$ & $(0.1413)$ & (0.1019) & $(0.1024)$ & $(0.9931)$ \\
\hline \multirow[t]{2}{*}{ lin_calend_year_prov3 } & 0.0723 & 0.1638 & 0.0588 & 0.1236 & 2.2624 \\
\hline & $(0.1136)$ & $(0.1441)$ & $(0.0811)$ & $(0.1040)$ & $(1.7325)$ \\
\hline \multirow[t]{2}{*}{ lin_calend_year_prov4 } & -0.0946 & -0.1524 & -0.0684 & -0.1094 & -1.0198 \\
\hline & $(0.1267)$ & $(0.1477)$ & $(0.0927)$ & $(0.1051)$ & $(1.2618)$ \\
\hline \multirow[t]{2}{*}{ lin_calend_year_prov5 } & -0.0813 & -0.0760 & -0.0593 & -0.0555 & 1.8419 \\
\hline & $(0.1067)$ & $(0.1194)$ & $(0.0795)$ & $(0.0868)$ & $(1.1761)$ \\
\hline \multirow[t]{2}{*}{ avg_UR_pe3-6 } & $-1.2836^{* * *}$ & $-1.4348^{* *}$ & $-0.9652^{* * *}$ & $-1.0724^{* * *}$ & -0.3037 \\
\hline & $(0.4509)$ & $(0.5863)$ & $(0.3262)$ & $(0.4140)$ & $(4.4775)$ \\
\hline \multirow[t]{2}{*}{ Min_UR_pe0-6 } & -0.5718 & -0.4848 & -0.3128 & -0.2511 & -6.4742 \\
\hline & $(0.6219)$ & $(0.6613)$ & $(0.4391)$ & $(0.4664)$ & $(7.1097)$ \\
\hline \multirow[t]{2}{*}{ Birth cohort76 } & 0.7043 & -0.3300 & 0.5421 & -0.1909 & $-13.2641^{* * *}$ \\
\hline & $(0.5632)$ & $(0.7686)$ & $(0.4125)$ & $(0.5583)$ & $(3.6802)$ \\
\hline Birth cohort78 & 0.4261 & -0.0504 & 0.3188 & -0.0190 & $-5.9156^{* *}$ \\
\hline & $(0.3677)$ & $(0.4687)$ & $(0.2691)$ & $(0.3409)$ & $(2.5815)$ \\
\hline Live in single-parent & 0.3453 & 0.7897 & 0.2731 & 0.5880 & 6.1392 \\
\hline & $(0.4632)$ & $(0.5207)$ & $(0.3466)$ & $(0.3840)$ & $(4.1354)$ \\
\hline Not live with parents & $0.4272^{*}$ & 0.5203 & $0.3476^{*}$ & 0.4136 & 1.0913 \\
\hline & $(0.2431)$ & $(0.3501)$ & $(0.1792)$ & $(0.2530)$ & $(2.5611)$ \\
\hline HH members aged 0-11 & -0.0177 & 0.0846 & -0.0462 & 0.0263 & 1.3007 \\
\hline & $(0.1123)$ & $(0.1472)$ & $(0.0878)$ & $(0.1069)$ & (1.1570) \\
\hline
\end{tabular}


Table 7 Complete estimations on continuous outcomes (Continued)

\begin{tabular}{|c|c|c|c|c|c|}
\hline \multirow[t]{2}{*}{ HH members aged 12-17 } & 0.1680 & 0.1467 & 0.1261 & 0.1110 & -0.2429 \\
\hline & $(0.1177)$ & $(0.1473)$ & $(0.0883)$ & $(0.1087)$ & $(0.9030)$ \\
\hline \multirow[t]{2}{*}{ HH members aged 18-29 } & 0.0112 & 0.2054 & 0.0073 & 0.1449 & $2.6587^{* *}$ \\
\hline & $(0.1164)$ & $(0.1561)$ & $(0.0870)$ & $(0.1134)$ & $(1.0291)$ \\
\hline \multirow[t]{2}{*}{ HH members aged 30-64 } & -0.0334 & -0.0801 & -0.0112 & -0.0443 & -0.4836 \\
\hline & $(0.4065)$ & $(0.4287)$ & $(0.3022)$ & $(0.3129)$ & $(3.2574)$ \\
\hline \multirow[t]{2}{*}{ HH members aged 65+ } & -0.0680 & 0.0308 & -0.0289 & 0.0411 & 1.2468 \\
\hline & $(0.3639)$ & $(0.4196)$ & $(0.2683)$ & $(0.3079)$ & (3.1042) \\
\hline \multirow[t]{2}{*}{ Father education } & 0.0011 & 0.0294 & 0.0000 & 0.0201 & 0.3816 \\
\hline & $(0.0255)$ & $(0.0330)$ & $(0.0188)$ & $(0.0240)$ & $(0.2531)$ \\
\hline \multirow[t]{2}{*}{ Mother education } & $-0.1053^{* * *}$ & -0.0485 & $-0.0765^{* * *}$ & -0.0363 & $0.7800^{* *}$ \\
\hline & $(0.0356)$ & $(0.0432)$ & $(0.0269)$ & $(0.0317)$ & $(0.2925)$ \\
\hline \multirow[t]{2}{*}{ Years of delay in sec. edu } & -0.0545 & $0.3485^{*}$ & -0.0423 & 0.2433 & $5.4123^{* * *}$ \\
\hline & $(0.1112)$ & $(0.2094)$ & $(0.0808)$ & $(0.1510)$ & $(1.1119)$ \\
\hline \multirow[t]{2}{*}{ Technical edu } & 0.4431 & -0.4557 & 0.3563 & -0.2807 & $-11.8663^{* * *}$ \\
\hline & $(0.3274)$ & $(0.4733)$ & $(0.2470)$ & (0.3399) & (2.9533) \\
\hline \multirow[t]{2}{*}{ Vocational edu } & 0.4572 & -0.3520 & $0.3675^{*}$ & -0.2059 & $-10.6291^{* * *}$ \\
\hline & $(0.2772)$ & $(0.4516)$ & $(0.2101)$ & $(0.3233)$ & (3.3428) \\
\hline \multirow[t]{2}{*}{ Apprenticeship/PT edu } & -0.1879 & $-1.1341^{*}$ & -0.1093 & $-0.7798^{*}$ & $-12.5300^{* *}$ \\
\hline & $(0.4530)$ & $(0.6234)$ & $(0.3375)$ & $(0.4500)$ & $(4.7050)$ \\
\hline \multirow[t]{2}{*}{ Constant } & $15.0564^{* * *}$ & $18.1335^{* * *}$ & $10.7790^{* * *}$ & $12.9598^{* * *}$ & 24.5592 \\
\hline & (3.7529) & $(5.2571)$ & $(2.6949)$ & $(3.7277)$ & (49.3992) \\
\hline Observations & 1,902 & 1,902 & 1,902 & 1,902 & 1,902 \\
\hline R-squared & 0.0895 & -0.2401 & 0.0895 & -0.2099 & 0.1070 \\
\hline F stat of first step $b$ & & & & & 10.51 \\
\hline Exogeneity test $\mathrm{P}$-val ${ }^{\mathrm{C}}$ & & 0.00970 & & 0.0112 & \\
\hline
\end{tabular}

Standard errors between parentheses. Columns 1-4 report the results from estimating Eq. (2) by OLS (odds columns) and 2SLS (even columns). Column 5 reports OLS results from estimating the first stage. All estimations report cluster-robust standard errors by graduation year $g$ and province of residence at graduation $p(G=44)$. Column 5 reports the

$F$ statistic of the first stage and even columns report the exogeneity test for early non-employment $\left(y_{i t}^{0}\right)$ ${ }^{* * *} p<0.01,{ }^{* *} p<0.05,{ }^{*} p<0.1$

${ }^{a}$ Continuous outcomes are measured at potential experience 6; early non-employment is measured at potential experience $0-2$. For continuous outcomes we add value one before taking the logarithm, so that those who are not salaried employed at the moment of evaluation are included with outcomes equal to zero after the logarithmic transformation

${ }^{b}$ This statistic is not corrected for the problem of few clusters. The corrected value resulting from the bootstrap procedure is 9.25 (see Table 1)

'With clustered standard errors, the exogeneity test is defined as the difference between two Sargan-Hansen statistics: one for the equation where $y_{i t 1}^{0}$ is treated as endogenous and one for the equation where $y_{i t_{1}}^{0}$ is treated as exogenous. Under the null that $y_{i t_{1}}^{0}$ is exogenous, the statistic is distributed as $\chi^{2}(1)$. This statistic is not corrected for the problem of few clusters 
Table 8 Complete estimations on binary outcomes

\begin{tabular}{|c|c|c|c|c|c|c|}
\hline \multirow{3}{*}{ Outcomes:a } & \multicolumn{6}{|c|}{ Second stage } \\
\hline & \multicolumn{2}{|c|}{ Salaried empl. } & \multicolumn{2}{|c|}{ Self-empl. } & \multicolumn{2}{|c|}{ Overall empl. } \\
\hline & OLS & $2 S L S$ & OLS & $2 S L S$ & OLS & $2 S L S$ \\
\hline \multirow[t]{2}{*}{ Clustered standard errors: } & $g * p$ & $g * p$ & $g * p$ & $g * p$ & $g * p$ & $g * p$ \\
\hline & $(1)$ & $(2)$ & (3) & (4) & (5) & (6) \\
\hline \multirow[t]{2}{*}{ Early non-empl. } & $-0.00169^{* * *}$ & -0.00256 & 0.00054 & 0.00248 & $-0.00115^{* * *}$ & -0.00008 \\
\hline & $(0.00041)$ & $(0.00290)$ & $(0.00041)$ & $(0.00258)$ & $(0.00025)$ & $(0.00151)$ \\
\hline \multirow[t]{2}{*}{ UR_pe6 } & 0.00481 & 0.00404 & 0.01081 & 0.01253 & 0.01562 & $0.01657^{*}$ \\
\hline & $(0.02385)$ & $(0.02209)$ & $(0.01947)$ & $(0.01765)$ & $(0.01020)$ & $(0.00999)$ \\
\hline \multirow[t]{2}{*}{ lin_grad_year } & -0.00253 & -0.00009 & -0.01367 & -0.01911 & -0.01621 & -0.01920 \\
\hline & $(0.03120)$ & $(0.03028)$ & $(0.02544)$ & $(0.02343)$ & $(0.01397)$ & $(0.01340)$ \\
\hline \multirow[t]{2}{*}{ lin_grad_year|trend >3 } & 0.02993 & 0.02680 & 0.00338 & 0.01032 & $0.03331^{*}$ & $0.03712^{* *}$ \\
\hline & $(0.04020)$ & $(0.04043)$ & $(0.03029)$ & $(0.02903)$ & $(0.01832)$ & $(0.01813)$ \\
\hline \multirow[t]{2}{*}{ lin_grad_year|trend >6 } & -0.01720 & -0.01695 & 0.01884 & 0.01829 & 0.00164 & 0.00134 \\
\hline & $(0.02568)$ & $(0.02477)$ & $(0.02503)$ & $(0.02252)$ & $(0.01457)$ & $(0.01375)$ \\
\hline \multirow[t]{2}{*}{ d_province2 } & $-0.22288^{* *}$ & $-0.22144^{* *}$ & $0.17666^{*}$ & $0.17347^{* *}$ & -0.04621 & -0.04797 \\
\hline & $(0.09844)$ & $(0.09548)$ & $(0.09049)$ & $(0.08719)$ & $(0.04174)$ & $(0.03996)$ \\
\hline \multirow[t]{2}{*}{ d_province3 } & $-0.17150^{* * *}$ & $-0.18038^{* * *}$ & $0.13845^{* *}$ & $0.15820^{* *}$ & -0.03304 & -0.02218 \\
\hline & $(0.06193)$ & $(0.06407)$ & $(0.06588)$ & $(0.06577)$ & $(0.03720)$ & $(0.04285)$ \\
\hline \multirow[t]{2}{*}{ d_province4 } & $-0.11409^{* *}$ & $-0.11292^{* *}$ & $0.10736^{* *}$ & $0.10477^{* *}$ & -0.00673 & -0.00816 \\
\hline & $(0.04892)$ & $(0.04910)$ & $(0.04459)$ & $(0.04794)$ & $(0.02450)$ & $(0.02611)$ \\
\hline \multirow[t]{2}{*}{ d_province5 } & 0.04132 & 0.04158 & -0.06171 & -0.06229 & -0.02039 & -0.02071 \\
\hline & $(0.06183)$ & $(0.06032)$ & $(0.04557)$ & $(0.04483)$ & $(0.03418)$ & $(0.03449)$ \\
\hline \multirow[t]{2}{*}{ lin_calend_year_prov2 } & 0.01976 & 0.01966 & -0.01544 & -0.01521 & 0.00432 & 0.00445 \\
\hline & $(0.01597)$ & $(0.01524)$ & $(0.01253)$ & $(0.01214)$ & $(0.00565)$ & $(0.00651)$ \\
\hline \multirow[t]{2}{*}{ lin_calend_year_prov3 } & -0.00496 & -0.00387 & 0.00501 & 0.00259 & 0.00005 & -0.00128 \\
\hline & $(0.01207)$ & $(0.01140)$ & $(0.01565)$ & $(0.01376)$ & $(0.00716)$ & $(0.00690)$ \\
\hline \multirow[t]{2}{*}{ lin_calend_year_prov4 } & 0.01299 & 0.01231 & -0.01369 & -0.01217 & -0.00070 & 0.00014 \\
\hline & $(0.01118)$ & $(0.01157)$ & $(0.00964)$ & $(0.01055)$ & $(0.00642)$ & $(0.00679)$ \\
\hline \multirow[t]{2}{*}{ lin_calend_year_prov5 } & -0.00608 & -0.00602 & 0.01656 & $0.01642^{*}$ & $0.01048^{* *}$ & $0.01041^{* *}$ \\
\hline & $(0.01074)$ & $(0.01027)$ & $(0.01012)$ & $(0.00967)$ & $(0.00471)$ & $(0.00491)$ \\
\hline \multirow[t]{2}{*}{ avg_UR_pe3-6 } & $-0.08309^{* *}$ & $-0.08489 * *$ & 0.03333 & 0.03733 & $-0.04976^{*}$ & $-0.04756^{*}$ \\
\hline & $(0.04062)$ & $(0.04005)$ & $(0.03418)$ & $(0.03230)$ & $(0.02622)$ & $(0.02516)$ \\
\hline Min_UR_pe0-6 & -0.01193 & -0.01089 & 0.00452 & 0.00222 & -0.00741 & -0.00867 \\
\hline & $(0.06247)$ & $(0.05970)$ & $(0.05849)$ & $(0.05672)$ & $(0.02769)$ & $(0.02854)$ \\
\hline Birth cohort76 & 0.00488 & -0.00741 & 0.01471 & 0.04204 & 0.01959 & 0.03462 \\
\hline & $(0.04397)$ & $(0.06402)$ & $(0.03588)$ & $(0.05434)$ & $(0.02535)$ & $(0.03517)$ \\
\hline Birth cohort78 & 0.02309 & 0.01743 & -0.00086 & 0.01173 & 0.02223 & 0.02916 \\
\hline & $(0.03666)$ & $(0.04407)$ & $(0.03059)$ & $(0.03645)$ & $(0.01745)$ & $(0.02152)$ \\
\hline live in single-parent & -0.00309 & 0.00220 & -0.03561 & -0.04736 & -0.03870 & -0.04516 \\
\hline & $(0.05525)$ & $(0.05471)$ & $(0.05233)$ & $(0.05472)$ & $(0.03217)$ & $(0.03371)$ \\
\hline Not live with parents & 0.02521 & 0.02631 & -0.01502 & -0.01748 & 0.01019 & 0.00883 \\
\hline & $(0.02900)$ & $(0.02995)$ & $(0.02753)$ & $(0.03031)$ & $(0.01581)$ & $(0.01592)$ \\
\hline HH members aged 0-11 & -0.00246 & -0.00124 & 0.00596 & 0.00325 & 0.00350 & 0.00201 \\
\hline & $(0.01217)$ & $(0.01251)$ & $(0.01277)$ & $(0.01265)$ & $(0.00574)$ & $(0.00627)$ \\
\hline HH members aged 12-17 & $0.02291^{*}$ & $0.02265^{*}$ & -0.01252 & -0.01196 & 0.01039 & 0.01070 \\
\hline & $(0.01185)$ & $(0.01173)$ & $(0.01041)$ & $(0.01069)$ & $(0.00709)$ & $(0.00683)$ \\
\hline HH members aged 18-29 & 0.00009 & 0.00240 & 0.00374 & -0.00139 & 0.00384 & 0.00101 \\
\hline & $(0.01152)$ & $(0.01355)$ & $(0.01034)$ & $(0.01150)$ & $(0.00604)$ & $(0.00688)$ \\
\hline HH members aged 30-64 & -0.01697 & -0.01752 & -0.02276 & -0.02152 & -0.03972 & -0.03904 \\
\hline & $(0.05212)$ & $(0.05087)$ & $(0.04874)$ & $(0.04896)$ & $(0.02847)$ & $(0.02961)$ \\
\hline
\end{tabular}


Table 8 Complete estimations on binary outcomes (Continued)

\begin{tabular}{lcccccc}
\hline HH members aged 65+ & -0.02001 & -0.01884 & 0.00730 & 0.00469 & -0.01271 & -0.01414 \\
& $(0.04165)$ & $(0.04136)$ & $(0.03573)$ & $(0.03540)$ & $(0.02182)$ & $(0.02205)$ \\
Father education & -0.00132 & -0.00099 & 0.00045 & -0.00030 & -0.00087 & -0.00128 \\
& $(0.00198)$ & $(0.00226)$ & $(0.00202)$ & $(0.00213)$ & $(0.00160)$ & $(0.00170)$ \\
Mother education & $-0.00971^{* * *}$ & $-0.00904^{* *}$ & $0.00937^{* * *}$ & $0.00787^{* *}$ & -0.00034 & -0.00116 \\
& $(0.00341)$ & $(0.00417)$ & $(0.00294)$ & $(0.00327)$ & $(0.00181)$ & $(0.00210)$ \\
Years of delay in sec.edu & 0.00440 & 0.00919 & $-0.02391^{* *}$ & $-0.03456^{*}$ & $-0.01952^{* * *}$ & $-0.02537^{*}$ \\
& $(0.01275)$ & $(0.02067)$ & $(0.01070)$ & $(0.01764)$ & $(0.00702)$ & $(0.01381)$ \\
Technical edu & 0.01038 & -0.00031 & 0.02957 & 0.05333 & $0.03995^{* * *}$ & $0.05301^{* *}$ \\
& $(0.03694)$ & $(0.04459)$ & $(0.03180)$ & $(0.04181)$ & $(0.01452)$ & $(0.02678)$ \\
Vocational edu & 0.00818 & -0.00144 & 0.03776 & 0.05914 & $0.04594^{* * *}$ & $0.05770^{* *}$ \\
& $(0.03164)$ & $(0.04096)$ & $(0.02700)$ & $(0.04065)$ & $(0.01546)$ & $(0.02569)$ \\
Apprenticeship/PT edu & -0.06240 & -0.07366 & $0.08533^{*}$ & $0.11033^{* *}$ & 0.02292 & 0.03667 \\
& $(0.05336)$ & $(0.06364)$ & $(0.04311)$ & $(0.05434)$ & $(0.02842)$ & $(0.03967)$ \\
Constant & $1.41749^{* * *}$ & $1.45409^{* * *}$ & -0.15519 & -0.23651 & $1.26230^{* * *}$ & $1.21757^{* * *}$ \\
& $(0.35242)$ & $(0.37325)$ & $(0.32471)$ & $(0.34533)$ & $(0.20910)$ & $(0.22952)$ \\
Observations & 1,902 & 1,902 & 1,902 & 1,902 & 1,902 & 1,902 \\
R-squared & 0.04170 & 0.03730 & 0.03098 & 0.00332 & 0.05818 & 0.03540 \\
Exogeneity test $P$-val $b$ & & 0.767 & & 0.438 & & 0.467 \\
\hline
\end{tabular}

Standard errors between parentheses. Columns 1-6 report the results from estimating Eq. (2) by OLS (odds columns) and 2SLS (even columns). The first stage regression is reported in Table 7 (Column 5). All estimations report cluster-robust standard errors by graduation year $g$ and province of residence at graduation $p(G=44)$. Even columns report the exogeneity test for early non-employment $\left(y_{i t_{1}}^{0}\right)$, which is measured at potential experience $0-2$ ${ }^{* * *} p<0.01,{ }^{* *} p<0.05,{ }^{*} p<0.1$

${ }^{a}$ The binary outcomes are measured at potential experience 6

${ }^{b}$ With clustered standard errors, the exogeneity test is defined as the difference between two Sargan-Hansen statistics: one for the equation where $y_{i t_{1}}^{0}$ is treated as endogenous and one for the equation where $y_{i t_{1}}^{0}$ is treated as exogenous. Under the null that $y_{i 1_{1}}^{0}$ is exogenous, the statistic is distributed as $\chi^{2}(1)$. This statistic is not corrected for the problem of few clusters 


\section{Sensitivity analysis}

Table 9 Effect of interest excluding $\overline{U R}_{p}$ and $\min U R_{p t}$ from the specification

\begin{tabular}{|c|c|c|c|c|c|}
\hline \multirow[b]{3}{*}{ Outcomes: ${ }^{b}$} & \multicolumn{5}{|c|}{ Panel A: Effect of early non-employment in the structural equation: } \\
\hline & \multirow[b]{2}{*}{ Standard errors $^{a}$} & \multicolumn{2}{|c|}{ OLS } & \multicolumn{2}{|c|}{$2 S L S$} \\
\hline & & $\begin{array}{l}\text { Robust } \\
\text { (1) }\end{array}$ & $\begin{array}{c}\text { Cluster } g * p \\
\text { (2) }\end{array}$ & $\begin{array}{l}\text { Robust } \\
\text { (3) }\end{array}$ & $\begin{array}{c}\text { Cluster } g * p \\
(4)\end{array}$ \\
\hline \multirow[t]{5}{*}{ Salaried employment } & coeff & $-0.00169^{* * *}$ & $-0.00169^{* * *}$ & -0.00199 & -0.00199 \\
\hline & se & $(0.00034)$ & $(0.00041)$ & $(0.00387)$ & $(0.00348)$ \\
\hline & $P$-val & & 0.00019 & & 0.57020 \\
\hline & Bootstrap $P$-val ${ }^{c}$ & & 0.00000 & & 0.62462 \\
\hline & Exogeneity test $P$-val ${ }^{d}$ & & & 0.937 & 0.931 \\
\hline \multirow[t]{5}{*}{ Self-employment } & coeff & $0.00054^{*}$ & 0.00054 & 0.00219 & 0.00219 \\
\hline & se & $(0.00030)$ & $(0.00041)$ & $(0.00340)$ & $(0.00313)$ \\
\hline & $P$-val & & 0.19253 & & 0.48668 \\
\hline & Bootstrap $P$-val & & 0.19219 & & 0.52853 \\
\hline & Exogeneity test $P$-val & & 0.619 & & 0.587 \\
\hline \multirow[t]{5}{*}{ Overall employment } & coeff & $-0.00115^{* * *}$ & $-0.00115^{* * *}$ & 0.00020 & 0.00020 \\
\hline & se & $(0.00021)$ & $(0.00025)$ & $(0.00229)$ & $(0.00164)$ \\
\hline & $P$-val & & 0.00005 & & 0.90232 \\
\hline & Bootstrap $P$-val & & 0.00000 & & 0.91291 \\
\hline & Exogeneity test $P$-val & & & 0.540 & 0.386 \\
\hline \multirow[t]{5}{*}{ Log earnings } & coeff & $-0.0269^{* * *}$ & $-0.0269^{* * *}$ & $-0.0947^{* *}$ & $-0.0947^{* * *}$ \\
\hline & se & $(0.0033)$ & $(0.0040)$ & $(0.0447)$ & $(0.0354)$ \\
\hline & $P$-val & & $2.78 \mathrm{E}-08$ & & 0.01051 \\
\hline & Bootstrap $P$-val & & 0 & & 0.03003 \\
\hline & Exogeneity test $P$-val & & & & 0.0361 \\
\hline \multirow[t]{5}{*}{ Log hours worked } & coeff & $-0.0203^{* * *}$ & $-0.0203^{* * *}$ & $-0.0666^{* *}$ & $-0.0666^{* * *}$ \\
\hline & se & $(0.0024)$ & $(0.0029)$ & $(0.0326)$ & $(0.0251)$ \\
\hline & $P$-val & & $1.05 \mathrm{E}-08$ & & 0.01105 \\
\hline & Bootstrap $P$-val & & 0 & & 0.03403 \\
\hline & Exogeneity test $P$-val & & & & 0.0481 \\
\hline \multicolumn{6}{|c|}{ Panel B: Effect of the instrument from the first stage (OLS) } \\
\hline Outcome: & Standard errors: & Robust & Cluster $\left(g^{*} p\right)$ & & \\
\hline \multirow[t]{6}{*}{ Early non-empl. } & Coeff & $5.0319^{* * *}$ & $5.0319^{* * *}$ & & \\
\hline & se & $(1.6519)$ & $(1.7139)$ & & \\
\hline & $P$-val & & 0.0053 & & \\
\hline & Bootstrap $P$-val & & 0.0120 & & \\
\hline & F stat & & 8.620 & & \\
\hline & Bootstrap F stat ${ }^{e}$ & & 5.84 & & \\
\hline
\end{tabular}

Standard errors between parentheses. Panel A reports results from estimating $\beta$ in Eq. (2), excluding $\overline{U R}_{p}$ and $\min U R_{p t} . \beta$ is the effect of one $p p$ increase in $y_{i t,}^{0}$, i.e. the $\%$ of hours spent in non-employment at potential experience $0-2$ relative to potential total hours if one would work full-time during the whole period. For clustered standard errors, we report the $P$-value and the wild bootstrap $P$-value. Column 1-2 (3-4) show OLS (2SLS). In 2 SLS the provincial unemployment rate at graduation is used as instrument for $y_{i t_{1}}^{0}$. Panel $\mathrm{B}$ reports the effect of the instrument on $y_{i t_{1}}^{0}$ in the first stage and the corresponding F statistic

${ }^{* * *} p<0.01,{ }^{* *} p<0.05,{ }^{*} p<0.1$

${ }^{a}$ Robust indicates heteroskedastic-robust standard errors. Clusters are defined by graduation year $g$ and province of residence at graduation $p$ ( $\mathrm{G}=44$ clusters)

${ }^{b}$ The outcomes are measured at potential experience 6 . For continuous outcomes we add value one before taking the log, so that non-salaried employed at the moment of evaluation are included with outcomes equal to zero after the logarithmic transformation

CComputed according to the wild bootstrap procedure proposed by Davidson and MacKinnon (2010) for 999 repetitions

${ }^{d}$ With clustered standard errors, this test is defined as the difference between two Sargan-Hansen statistics: one for the equation where $y_{i t_{1}}^{0}$ is treated as endogenous and one for the equation where $y_{i t_{1}}^{0}$ is treated as exogenous. Under the null that $y_{i t_{1}}^{0}$ is exogenous, the statistic is distributed as $\chi^{2}(1)$

${ }^{e}$ Bootstrap F statistic is the $\mathrm{F}$ statistic corresponding to the Bootstrap $P$-value of the $t$ statistic of the instrument: we rely on the equivalence between $F$ and $t$ distribution: with $G=44, t^{2}(G-1)=F(1, G-1)$ 
Table 10 Effect of interest for graduation period 1998-2002

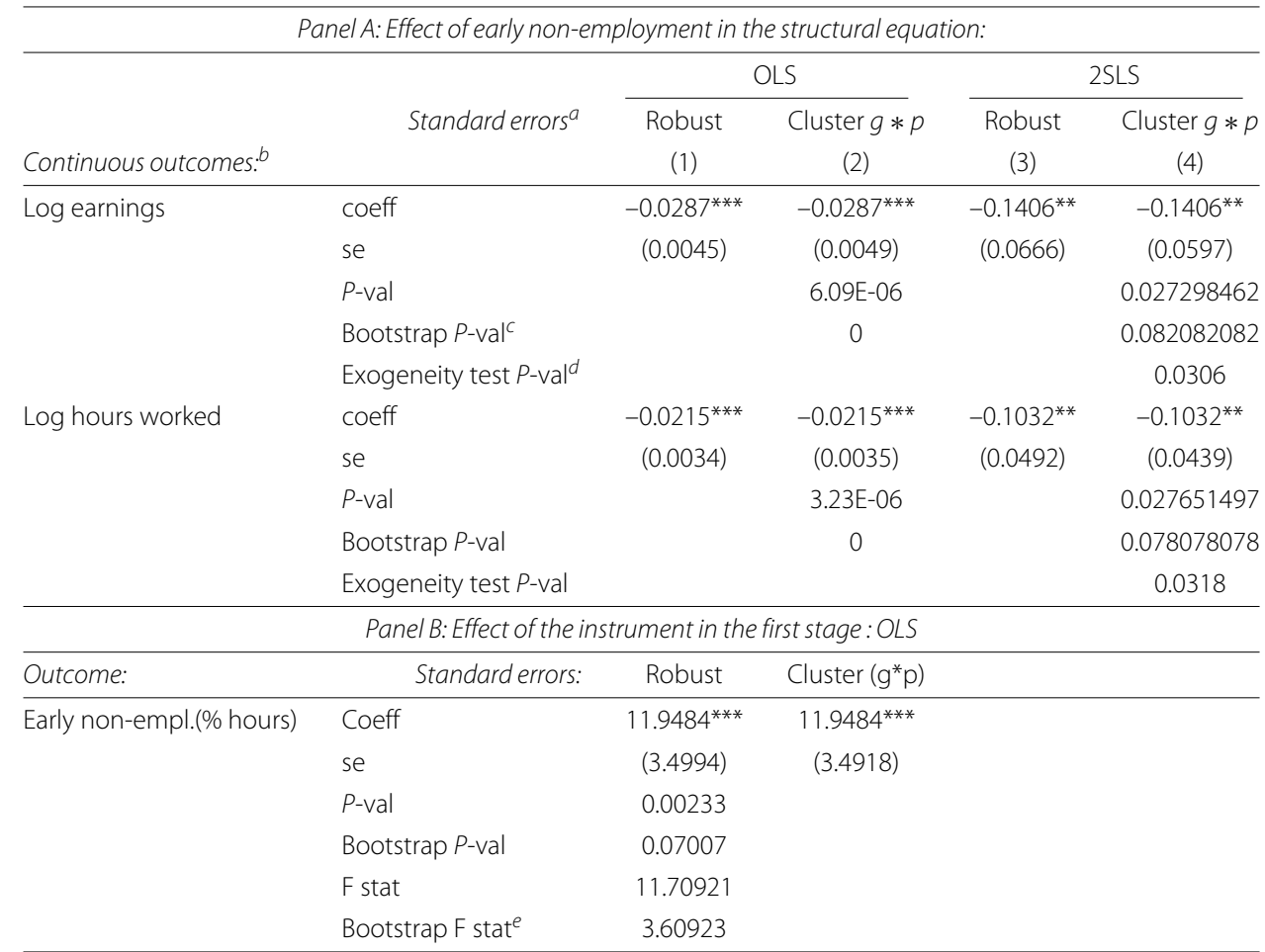

Standard errors between parentheses. Panel A reports results from estimating $\beta$ in Eq. (2). $\beta$ is the effect of one $p p$ increase in $y_{i t_{1}}^{0}$, i.e. the $\%$ of hours spent in non-employment at potential experience $0-2$ relative to potential total hours if one would work full-time during the whole period. For clustered standard errors, we report the $P$-value and the wild bootstrap $P$-value. Column 1-2 (3-4) show OLS (2SLS). In 2SLS the provincial unemployment rate at graduation is used as instrument for $y_{i t_{1}}^{0}$. Panel $B$ shows the effect of the instrument on $y_{i t_{1}}^{0}$ in the first stage and the corresponding F statistic ${ }^{* * *} p<0.01,{ }^{* *} p<0.05,{ }^{*} p<0.1$

${ }^{a}$ Robust indicates heteroskedastic-robust standard errors. Clusters are defined by graduation year $g$ and province of residence at graduation $p$ ( $\mathrm{G}=24$ clusters)

${ }^{b}$ The outcomes are measured at potential experience 6 . For continuous outcomes we add value one before taking the log, so that non-salaried employed at the moment of evaluation are included with outcomes equal to zero after the logarithmic transformation

${ }^{c}$ Computed according to the wild bootstrap procedure proposed by Davidson and MacKinnon (2010) for 999 repetitions ${ }^{d}$ With clustered standard errors, this test is defined as the difference between two Sargan-Hansen statistics: one for the equation where $y_{i t_{1}}^{0}$ is treated as endogenous and one for the equation where $y_{i t_{1}}^{0}$ is treated as exogenous. Under the null that $y_{i t_{1}}^{0}$ is exogenous, the statistic is distributed as $\chi^{2}(1)$

${ }^{e}$ Bootstrap $\mathrm{F}$ statistic is the $\mathrm{F}$ statistic corresponding to the bootstrap $P$-value of the t statistic of the instrument: we rely on the equivalence between $\mathrm{F}$ and $\mathrm{t}$ distribution: $t^{2}(G-1)=F(1, G-1)$, with $G=24$ 
Table 11 Complete OLS: period 1994-2002 vs 1998-2002; full vs restricted specification

\begin{tabular}{|c|c|c|c|c|c|c|}
\hline \multirow[t]{4}{*}{ Continuous outcomes ${ }^{a}$ : } & \multicolumn{3}{|c|}{ Log earnings } & \multicolumn{3}{|c|}{ Log hours worked } \\
\hline & \multicolumn{2}{|c|}{ g94-02 } & g98-02 & \multicolumn{2}{|c|}{ g94-02 } & g98-02 \\
\hline & \multirow{2}{*}{$\frac{\text { full spec. }^{d}}{(1)}$} & \multicolumn{2}{|c|}{ Restricted spec.e $^{e}$} & \multirow{2}{*}{$\frac{\text { Full spec. }}{(4)}$} & \multicolumn{2}{|c|}{ Restricted spec. } \\
\hline & & (2) & (3) & & (5) & (6) \\
\hline Cluster & $g * p$ & $g * p$ & $g * p$ & $g * p$ & $g * p$ & $g * p$ \\
\hline \multirow[t]{2}{*}{ Early non-empl (\% hours) } & $-0.027^{* * *}$ & $-0.027^{* * *}$ & $-0.029^{* * *}$ & $-0.020^{* * *}$ & $-0.020^{* * *}$ & $-0.022^{* * *}$ \\
\hline & $(0.004)$ & $(0.004)$ & $(0.005)$ & $(0.003)$ & $(0.003)$ & $(0.004)$ \\
\hline \multirow[t]{2}{*}{ UR_pe6 } & $0.482^{* *}$ & $0.617^{* * *}$ & 0.594 & $0.334^{* *}$ & $0.432^{* * *}$ & 0.445 \\
\hline & $(0.190)$ & $(0.179)$ & $(0.544)$ & $(0.138)$ & $(0.130)$ & $(0.393)$ \\
\hline \multirow[t]{2}{*}{ lin_grad_year } & -0.159 & -0.114 & $0.811^{*}$ & -0.114 & -0.082 & $0.635^{*}$ \\
\hline & $(0.294)$ & $(0.284)$ & $(0.460)$ & $(0.213)$ & $(0.205)$ & $(0.333)$ \\
\hline \multirow[t]{2}{*}{ lin_grad_year|trend >3 } & $0.903^{* *}$ & $0.661^{*}$ & -1.032 & $0.668^{* *}$ & $0.492^{*}$ & -0.795 \\
\hline & $(0.400)$ & $(0.360)$ & $(0.701)$ & $(0.292)$ & $(0.260)$ & $(0.503)$ \\
\hline \multirow[t]{2}{*}{ lin_grad_year|trend > 6} & $-0.460^{*}$ & & & $-0.334^{*}$ & & \\
\hline & $(0.258)$ & & & $(0.187)$ & & \\
\hline \multirow[t]{2}{*}{ avg_UR_pe3-6 } & $-1.284^{* * *}$ & $-0.826^{* *}$ & -1.879 & $-0.965^{* * *}$ & $-0.634^{* *}$ & -1.481 \\
\hline & $(0.451)$ & $(0.394)$ & $(1.373)$ & $(0.326)$ & $(0.289)$ & $(0.993)$ \\
\hline \multirow[t]{2}{*}{ min_UR_pe0-6 } & -0.572 & -0.692 & $-3.140^{* * *}$ & -0.313 & -0.398 & $-2.204^{* *}$ \\
\hline & $(0.622)$ & $(0.590)$ & $(1.118)$ & $(0.439)$ & $(0.419)$ & $(0.791)$ \\
\hline \multirow[t]{2}{*}{ d_province2 } & $-1.381^{*}$ & -0.913 & $-4.627^{* * *}$ & $-0.948^{*}$ & -0.612 & $-3.214^{* *}$ \\
\hline & $(0.711)$ & $(0.704)$ & $(1.597)$ & $(0.504)$ & $(0.503)$ & $(1.169)$ \\
\hline \multirow[t]{2}{*}{ d_province3 } & $-2.175^{* * *}$ & $-1.756^{* * *}$ & $-4.127^{* *}$ & $-1.577^{* * *}$ & $-1.275^{* * *}$ & $-3.024^{* *}$ \\
\hline & $(0.607)$ & $(0.547)$ & $(1.740)$ & $(0.434)$ & $(0.392)$ & $(1.238)$ \\
\hline \multirow[t]{2}{*}{ d_province4 } & 0.084 & -0.109 & -1.617 & 0.074 & -0.069 & -1.118 \\
\hline & $(0.480)$ & $(0.456)$ & (1.380) & $(0.350)$ & $(0.333)$ & $(0.984)$ \\
\hline \multirow[t]{2}{*}{ d_province5 } & 0.899 & 0.741 & 1.125 & 0.667 & 0.552 & 0.743 \\
\hline & $(0.610)$ & $(0.609)$ & $(1.902)$ & $(0.450)$ & $(0.451)$ & $(1.397)$ \\
\hline \multirow[t]{2}{*}{ lin_calend_year_prov2 } & 0.050 & 0.075 & 0.126 & 0.035 & 0.055 & 0.064 \\
\hline & (0.139) & $(0.144)$ & $(0.307)$ & $(0.102)$ & $(0.106)$ & $(0.228)$ \\
\hline lin_calend_year_prov3 & 0.072 & 0.147 & -0.135 & 0.059 & 0.114 & -0.105 \\
\hline & $(0.114)$ & $(0.104)$ & $(0.137)$ & $(0.081)$ & $(0.075)$ & $(0.094)$ \\
\hline lin_calend_year_prov4 & -0.095 & -0.007 & -0.120 & -0.068 & -0.004 & -0.102 \\
\hline & $(0.127)$ & $(0.109)$ & $(0.304)$ & $(0.093)$ & $(0.080)$ & $(0.220)$ \\
\hline lin_calend_year_prov5 & -0.081 & -0.102 & -0.078 & -0.059 & -0.075 & -0.041 \\
\hline & $(0.107)$ & $(0.107)$ & $(0.357)$ & $(0.079)$ & $(0.080)$ & $(0.263)$ \\
\hline birth cohort76 & 0.704 & 0.813 & 0.816 & 0.542 & 0.622 & 0.625 \\
\hline & $(0.563)$ & $(0.510)$ & $(0.599)$ & $(0.413)$ & $(0.373)$ & $(0.437)$ \\
\hline birth cohort78 & 0.426 & 0.487 & 0.471 & 0.319 & 0.364 & 0.353 \\
\hline & $(0.368)$ & $(0.350)$ & $(0.353)$ & $(0.269)$ & $(0.255)$ & $(0.256)$ \\
\hline HH members aged 0-11 & -0.018 & 0.016 & 0.005 & -0.046 & -0.021 & -0.027 \\
\hline & $(0.112)$ & $(0.116)$ & $(0.136)$ & $(0.088)$ & $(0.090)$ & $(0.103)$ \\
\hline Father education & 0.001 & -0.002 & -0.017 & 0.000 & -0.003 & -0.014 \\
\hline & $(0.026)$ & $(0.025)$ & $(0.041)$ & $(0.019)$ & $(0.019)$ & $(0.031)$ \\
\hline Mother education & $-0.105^{* * *}$ & $-0.100^{* * *}$ & $-0.103^{* *}$ & $-0.077^{* * *}$ & $-0.073^{* * *}$ & $-0.074^{* *}$ \\
\hline & $(0.036)$ & $(0.035)$ & $(0.045)$ & $(0.027)$ & $(0.026)$ & $(0.033)$ \\
\hline Years of delay in sec. edu & -0.054 & -0.143 & -0.190 & -0.042 & -0.106 & -0.140 \\
\hline & $(0.111)$ & $(0.096)$ & $(0.166)$ & $(0.081)$ & $(0.071)$ & $(0.121)$ \\
\hline General edu & & -0.449 & -0.161 & & -0.361 & -0.145 \\
\hline & & $(0.299)$ & $(0.353)$ & & $(0.226)$ & $(0.265)$ \\
\hline
\end{tabular}


Table 11 Complete OLS: period 1994-2002 vs 1998-2002; full vs restricted specification (Continued)

\begin{tabular}{|c|c|c|c|c|c|c|}
\hline \multirow[t]{2}{*}{ Live in single-parent } & \multicolumn{3}{|l|}{0.345} & \multicolumn{3}{|l|}{0.273} \\
\hline & \multicolumn{3}{|l|}{$(0.463)$} & \multicolumn{3}{|l|}{$(0.347)$} \\
\hline \multirow[t]{2}{*}{ Not live with parents } & \multicolumn{3}{|l|}{$0.427^{*}$} & \multicolumn{3}{|l|}{$0.348^{*}$} \\
\hline & \multicolumn{3}{|l|}{$(0.243)$} & \multicolumn{3}{|l|}{$(0.179)$} \\
\hline \multirow[t]{2}{*}{ HH members aged 12-17 } & \multicolumn{3}{|l|}{0.168} & \multicolumn{3}{|l|}{0.126} \\
\hline & \multicolumn{3}{|l|}{$(0.118)$} & \multicolumn{3}{|l|}{$(0.088)$} \\
\hline \multirow[t]{2}{*}{ HH members aged 18-29 } & \multicolumn{3}{|l|}{0.011} & \multicolumn{3}{|l|}{0.007} \\
\hline & \multicolumn{3}{|l|}{$(0.116)$} & \multicolumn{3}{|l|}{$(0.087)$} \\
\hline \multirow[t]{2}{*}{ HH members aged 30-64 } & \multicolumn{3}{|l|}{-0.033} & \multicolumn{3}{|l|}{-0.011} \\
\hline & \multicolumn{3}{|l|}{$(0.407)$} & \multicolumn{3}{|l|}{$(0.302)$} \\
\hline \multirow[t]{2}{*}{ HH members aged $65+$} & \multicolumn{3}{|l|}{-0.068} & \multicolumn{3}{|l|}{-0.029} \\
\hline & \multicolumn{3}{|l|}{$(0.364)$} & \multicolumn{3}{|l|}{$(0.268)$} \\
\hline \multirow[t]{2}{*}{ Technical edu } & \multicolumn{3}{|l|}{0.443} & \multicolumn{3}{|l|}{0.356} \\
\hline & \multicolumn{3}{|l|}{$(0.327)$} & $(0.247)$ & & \\
\hline Vocational edu & 0.457 & & & $0.368^{*}$ & & \\
\hline & $(0.277)$ & & & $(0.210)$ & & \\
\hline Apprenticeship/PT edu & -0.188 & & & -0.109 & & \\
\hline & $(0.453)$ & & & $(0.337)$ & & \\
\hline Constant & $15.056^{* * *}$ & $12.908^{* * *}$ & $29.987^{* * *}$ & $10.779^{* * *}$ & $9.282^{* * *}$ & $22.069^{* * *}$ \\
\hline & $(3.753)$ & $(3.432)$ & $(7.716)$ & $(2.695)$ & $(2.454)$ & $(5.520)$ \\
\hline Observations & 1,902 & 1,902 & 946 & 1,902 & 1,902 & 946 \\
\hline R-squared & 0.090 & 0.084 & 0.097 & 0.089 & 0.084 & 0.098 \\
\hline $\begin{array}{l}\text { Standard errors between parer } \\
\text { they are equivalent to the estin } \\
\text { specification discussed for the } \\
\text { estimate the same restricted sp } \\
\text { Standard errors are clustered b } \\
{ }^{* * *} p<0.01,{ }^{* *} p<0.05,{ }^{*} p<0.1 \\
{ }^{a} \text { For continuous outcomes we } \\
\text { are included with outcomes ec } \\
{ }^{b} \text { Graduation period } 1994-2002 \\
{ }^{C} \text { Graduation period } 1998-2002 \\
{ }^{d} \text { The full specification correspo } \\
\text { eThe restricted specification is }\end{array}$ & $\begin{array}{l}\text { ses. Columns } \\
\text { ions reported } \\
\text { sitivity exercis } \\
\text { fication on the } \\
\text { raduation year } \\
\text { d value one be } \\
\text { to zero after t } \\
\text { nsidered } \\
\text { nsidered: for t } \\
\text { s to Eq. (2) } \\
\text { one used in th }\end{array}$ & $\begin{array}{l}\text { and } 4 \text { estimate } \\
\text { columns } 1 \text { and } \\
\text { Section } 5.1, b \\
\text { raduation peri } \\
\text { and province } \\
\text { re taking the lc } \\
\text { logarithmic tr } \\
\text { reason, the th } \\
\text { second sensiti }\end{array}$ & $\begin{array}{l}\text { (2) by OLS co } \\
\text { of Table 7. Colu } \\
\text { ed on the grad } \\
1998-2002, \text { wl } \\
\text { ving at gradua } \\
\text { so that non-sa } \\
\text { sformation } \\
\text { graduation ye } \\
\text { analysis in Sec }\end{array}$ & $\begin{array}{l}\text { dering the gra } \\
\text { ns } 2 \text { and } 5 \text { est } \\
\text { tion period } 19 \\
\text { his used in th } \\
\text { n } p \\
\text { ied employed } \\
\text { spline lin_grad } \\
5.1\end{array}$ & $\begin{array}{l}\text { uation period } \\
\text { ate the restri } \\
-2002 \text {. Colun } \\
\text { econd sensit } \\
\text { the moment } \\
\text { earltrend > }\end{array}$ & $\begin{array}{l}994-2002 \text { : } \\
\text { is } 3 \text { and } 6 \\
\text { ty analysis. } \\
\text { f evaluation } \\
\text { s omitted }\end{array}$ \\
\hline
\end{tabular}

\section{Additional file}

Additional file 1: Supplementary online appendix to "Scars of recessions in a rigid labour market". Relevant for this study are (i) Section S.5 of "Additional file 1" which discusses the test for the exogeneity of the timing of graduation; (ii) Section S.1.5 which provides a description of the unemployment rate series; (iii) Sections S.1, S.2 and S.3 which provide information on the construction of the variables. (PDF $530 \mathrm{~kb}$ )

\section{Abbreviations}

IV: Instrumental variable; EPL: Employment protection legislation; STC: Short-time work compensation; UI: Unemployment insurance; OLS: Ordinary least squares; LFS: Labour force survey; 2SLS: Two-stages least squares; $p$ : Percentage point.

\section{Competing interests}

The IZA Journal of European Labor Studies is committed to the IZA Guiding Principles of Research Integrity. The author declares that she has observed these principles.

\section{Acknowledgements}

I wish to thank Bart Cockx, William Parienté, Matteo Picchio, Bruno Van der Linden, Dieter Verhaest, Florian Mayneris and an anonymous referee for all their valuable comments and suggestions. I also thank the participants to the seminars at Ghent University (internal seminars) and the participants to the Doctoral Workshop at the Université catholique de Louvain for their comments. I am grateful to the Cross Roads Bank for Social Security and the "Steunpunt Studie- en Schoolloopbanen" for the availability of the data. I acknowledge financial support for this project from the Special Research Fund ("BOF") of Ghent University, as well as from the National Bank of Belgium (project code 05Y00110). I finally thank the Belgian Federal Administration Science Policy for its financial support in the project "Age, women and employment: An evaluation" within the program Society and Future (contract nr. TA/00/044)

Responsible editor: Sara de la Rica 
Received: 28 April 2015 Accepted: 13 August 2015

Published online: 13 October 2015

\section{References}

Angrist JD, Pischke J-S (2009) Mostly harmless econometrics. An empiricist's companion. Princeton University Press, Princeton and Oxford

Arulampalam W (2001) Is unemployment really scarring? Effects of unemployment experiences on wages. Econ J 111(475):585-606

Baltagi B, Kao C, Na S (2013) Testing for cross-sectional dependence in a panel factor model using the wild bootstrap F test. Stat Pap 54(4):1067-1094

Baum CF, Schaffer ME, Stillman S (2003) Instrumental variables and GMM: Estimation and testing. Stata J 3(1):1-31. 31

Beaudry P, DiNardo J (1991) The effect of implicit contracts on the movement of wages over the business cycle: evidence from micro data. J Pol Econ 99(4):665-688

Bell DN, Blanchflower DG (2010) Youth unemployment: Déjà Vu?. IZA Discussion Paper 4705, IZA, Bonn, Germany

Brunner B, Kuhn A (2014) The impact of labor market entry conditions on initial job assignment and wages. J Popul Econ 27(3):705-738

Cameron AC, Gelbach JB, Miller DL (2008) Bootstrap-based improvements for inference with clustered errors. Rev Econ Stat 90(3):414-427

Cockx B, Ghirelli C (2015) Scars of recessions in a rigid labor market. IZA Discussion Paper 8889, IZA, Bonn, Germany. Supplementary Online Appendix: http://users.ugent.be/ bcockx/Ascars.pdf

Cockx B, Picchio M (2013). Scarring effects of remaining unemployed for long-term unemployed school-leavers J R Stat Soc Ser A (Statistics in Society) 176(4):951-980

Davidson R, MacKinnon J (2010) Wild bootstrap tests for IV regression. J Bus \& Econ Stat 28(1):128-144

Davidson R, MacKinnon JG (2008) Bootstrap inference in a linear equation estimated by instrumental variables. Econ J 11(3):443-477

Devereux PJ, Hart RA (2007) The spot market matters: evidence on implicit contracts from Britain. Scott J Pol Econ 54(5):661-683

Ellwood DT (1982) Teenage unemployment: permanent scars or temporary blemishes? In: Freeman RB, Wise D-A (eds). The Youth Labor Market Problem: Its Nature, Causes, and Consequences, Chicago. University of Chicago Press. pp 349-390

Gangji AV, Plasman R (2007) The Matthew effect of unemployment: how does it affect wages in Belgium. DULBEA Working Papers 07-19. RS, Université Libre de Bruxelles, Brussels, Belgium

Gartell M (2009) Unemployment and subsequent earnings for Swedish college graduates. A study of scarring effects. Arbetsrapport 2009:2, Institute for Futures Studies, Stockholm, Sweden

Genda Y, Kondo A, Ohta S (2010) Long-term effects of a recession at labor market entry in Japan and the United States. J Hum Resour 45(1):157-196

Gervais M, Jaimovich N, Siu HE, Yedid-Levi Y (2014) What should I be when I grow up? Occupations and employment over the life cycle and business cycle. NBER Working Paper S 20628, NBER, Cambridge, MA

Gregg P (2001) The impact of youth unemployment on adult unemployment in the NCDS. Econ J 111 (475):626-653

Gregg P, Tominey E (2005) The wage scar from male youth unemployment. Labour Econ 12(4):487-509

Gregory M, Jukes R (2001) Unemployment and subsequent earnings: estimating scarring among British men 1984-94. Econ J 111(475):607-625

Hausman J (2001) Mismeasured variables in econometric analysis: problems from the right and problems from the left. J Econ Perspect 15(4):57-67

Heckman JJ (1979) Sample selection bias as a specification error. Econometrica 47(1):153-161

Kahn LB (2010) The long-term labor market consequences of graduating from college in a bad economy. Labour Econ 17(2):303-316

Kawaguchi D, Murao T (2014) Labor market institutions and long-term effects of youth unemployment. IZA Discussion Paper 8156. J Money Credit Bank 46(S2):95Ü116

Kilponen J, Santavirta T (2010) New evidence on implicit contracts from linked employer-employee data. Scandinavian J Econ 112(4):864-883

Kletzer LG, Fairlie RW (2003) The long-term costs of job displacement for young adult workers. Ind Labor Relat Rev 56(4):682-698

Lockwood B (1991) Information externalities in the labour market and the duration of unemployment. Rev Econ Stud 58(4):733-53

MacKinnon JG, Webb MD (2015) Wild bootstrap inference for wildly different cluster sizes. Queen's Economics Department Working Paper No. 1314, Queen's University, Kingston, Canada

Moulton BR (1990) An illustration of a pitfall in estimating the effects of aggregate variables on micro units. Rev Econ Stat 72(2):334

Mroz TA, Savage TH (2006) The long-term effects of youth unemployment. J Hum Resour 41(2):259-293

Neumark D (2002) Youth labor markets in the United States: shopping around vs. staying Put. Rev Econ Stat 84(3):462-482

Oreopoulos P, von Wachter T, Heisz A (2012) The short- and long-term career effects of graduating in a recession. Am Econ J: Appl Econ 4(1):1-29

Oreopoulos, P, von Wachter T, Heisz A (2008) The short- and long-term career effects of graduating in a recession: hysteresis and heterogeneity in the market for college graduates. IZA Discussion Paper 3578. IZA, Bonn, Germany

Pissarides CA (1992) Loss of skill during unemployment and the persistence of employment shocks. Quarterly J Econ 107(4):1371-1391

Puhani P (2000) The heckman correction for sample selection and its critique. J Econ Surv 14(1):53-68

Schmillen A, Umkehrer M (2013) The scars of youth: effects of early-career unemployment on future unemployment experience. IAB Discussion Paper 201306. IAB, Nürnberg, Germany 
Sonar (2003) Hoe maken de jongeren de overgang van school naar werk? Basisrapportering Cohorte 1978 (eerste golf), Tech. rep. Steunpunt WAV, Leuven, Belgium

Sonar (2004a) Hoe maken de jongeren de overgang van school naar werk? Basisrapportering Cohorte 1976 (tweede golf. Tech. rep. Steunpunt WAV, Leuven, Belgium

Sonar (2004b) Hoe maken de jongeren de overgang van school naar werk? Cohorte 1980 (eerste golf). Technisch rapport. Tech. rep. Steunpunt WAV, Leuven, Belgium

Stock J, Yogo M (2005) Testing for weak instruments in linear IV regression. In: Andrews DW (ed). Identification and Inference for Econometric Models. Cambridge University Press, New York. pp 80-108

Topel RH, Ward MP (1992) Job mobility and the careers of young men. Quarterly J Econ 107(2):439-79

Submit your manuscript to a SpringerOpen ${ }^{\circ}$ journal and benefit from:

- Convenient online submission

- Rigorous peer review

- Immediate publication on acceptance

- Open access: articles freely available online

- High visibility within the field

Retaining the copyright to your article

Submit your next manuscript at $\boldsymbol{\triangleright}$ springeropen.com 